\title{
Size-activity relationship of iridium particles supported on silica for the total oxidation of volatile organic compounds (VOCs)
}

Lukas Schick, ${ }^{a}$ Rut Sanchis, a Vicenta González-Alfaro, ${ }^{a}$ Said Agouram, ${ }^{\text {b José }}$ Manuel López, ${ }^{\mathrm{c}}$ Laura Torrente-Murciano, ${ }^{\mathrm{d}}$ Tomás García, ${ }^{\mathrm{c}, *}$ Benjamín Solsona ${ }^{\mathrm{a}, *}$

a Departament d'Enginyeria Química, ETSE, Universitat de València, Av. Universitat, 46100, Burjassot, Valencia, Spain. Benjamin.solsona@uv.es

${ }^{\mathrm{b}}$ Department of Applied Physics and Electromagnetism, Universitat de Valencia, C/Dr. Moliner 50, 46100 Burjassot, Valencia, Spain.

c Instituto de Carboquímica (CSIC), C/Miguel Luesma 4, 50018 Zaragoza, Spain. $\underline{\text { tomas@icb.csic.es }}$

${ }^{\mathrm{d}}$ Department of Chemical Engineering and Biotechnology, University of Cambridge, West Cambridge Site, Philippa Fawcett Drive, Cambridge, CB3 OAS, UK. 


\begin{abstract}
This systematic catalytic study reveals for the first time a strong size-activity relationship of iridium-based catalysts for the total oxidation of short chain alkanes reaction. Silica has been selected as support for its inertness and weak silica-iridium interaction to avoid its contribution to the catalytic activity. The size of the iridium particles can be increased from $\sim 5$ to $27 \mathrm{~nm}$ by increasing the calcination temperature from 350 to $750{ }^{\circ} \mathrm{C}$. Unlike other precious metals such as palladium or platinum, in the case of iridium catalysts, the oxidation activity increases when the size decreases. This effect is also maintained when the activity is normalized per metallic surface area revealing a higher intrinsic activity as the iridium size decreases beyond its simple increase in metallic surface area. Indeed, as the particle size decreases, a higher proportion of highly reducible iridium species as well as an increase in defective $\mathrm{Ir}^{3+}$ species on the surface is observed by XPS, directly related to the enhanced activity. The highly reducible species are oxidized under the reaction conditions, leading to an initial decrease in activity before reaching a stable rate of oxidation reaction. This knowledge provides useful guidelines for the design of iridium-based systems for the total oxidation of volatile organic compounds at low temperatures.
\end{abstract}

Keywords: Iridium; silica; VOC; short chain alkanes; total oxidation; size-activity relationship. 


\section{Introduction}

The emissions of volatile organic compounds (VOCs) to the atmosphere directly contribute to the formation of ozone and fine particles, known as smog, particularly detrimental in big cities. Therefore, VOCs are linked to health problems like heart disease and asthma [1] in addition of being toxic and carcinogenic by themselves [2]. The definition of VOCs is wide and includes chemically diverse compounds with a high vapour pressure under standard conditions, which participate in atmospheric photochemical reactions [3]. The main anthropogenic sources of VOCs include combustion processes, chemical and pharmaceutical plants, power generation, gas stations and textile manufacturing [3]. In addition, in recent years, the emission of VOCs from common household chemicals has risen [1]. Due to their toxicity and health risk, different methods for VOC abatement have been developed [4] including adsorption, absorption, condensation and thermal and catalytic total oxidation. Adsorption and absorption of VOCs are straight forward processes but they require periodic replacement and disposal of the saturated adsorbents. Condensation methods allow the re-utilisation of potentially expensive VOC compounds; however, these methods cannot normally ensure complete removal. On the other hand, destructive procedures such as thermal or catalytic oxidation of VOCs offer complete removal through their combustion to mainly carbon dioxide and water. The disadvantage of thermal oxidation is its requirement for high temperatures often exceeding $1000^{\circ} \mathrm{C}$, which makes thermal combustion fuel intensive and expensive. Catalytic oxidation, in contrast, requires moderate temperatures between $200^{\circ} \mathrm{C}$ and $500^{\circ} \mathrm{C}$, thanks to the role of a heterogeneous catalyst. Herein the required catalysts are often based on expensive noble metals and are specifically designed for a special VOC or VOC mixture. Catalytic oxidation is favoured in case of low VOC concentrations, when the influence of the 
reaction enthalpy on the catalyst temperature is low and hotspots in the catalyst bed are avoided [3].

Due to its potential, catalytic oxidation of VOCs has been extensively reviewed [2-3, 56] and it is now accepted that its efficiency depends on the specific chemical compound/s, the reaction conditions and the nature of the catalyst. In general, and as expected, the more stable a chemical compound is, the higher the temperature require for its total oxidation. Since alkanes and aromatics are very stable and often toxic or carcinogenic, their removal from air-like fluid streams is often the subject of investigation. For the total oxidation of alkanes, the activation of the $\mathrm{C}-\mathrm{H}$ bond is the rate determining step and therefore, the reactivity is inversely related to the energy of its weakest $\mathrm{C}-\mathrm{H}$ bond, resulting in methane as the most stable alkane followed by ethane, propane and butane [3].

Iridium-containing materials have been reported as useful catalysts for several reactions involving the activation of hydrocarbons and other compounds such as in hydrogenation reactions [7], reforming [8], isomerization [9], ring-opening reactions [10] and alkylation [11]. Iridium can also be an efficient component of multi-oxide catalysts together with other noble and non-noble metals such as platinum [12-14] or nickel [15].

In the total oxidation of propane, and in general in most of VOCs, the most active catalysts are based on Pt or Pd [5, 16-18]. Despite its comparable noble metal nature and close position in the elemental table, publications on supported iridium catalysts for total oxidation of VOCs are rare. Wang et al. investigated the stability of noble metals (Ir, Pt, Pd and Rh) on silica surfaces where iridium metal showed the lowest mobility and the most stable oxide $\left(\mathrm{IrO}_{2}\right)$ amongst the noble metals under investigation. The kinetic rates for oxidation and reduction of iridium were the slowest of any of the four 
metals studied [19]. In contrast, Wynblatt and Gjostein reported the stability against sintering of noble metals in the order $\mathrm{Ru}<\mathrm{Ir}<\mathrm{Pt}<\mathrm{Pd}$, $\mathrm{Rh}$ [20], which is in great agreement with the results reported by Fiedorow et al. for oxygen containing atmospheres, however, under reducing condition the sintering stability trend varies as Ir $>\mathrm{Rh}>\mathrm{Pt}[21]$.

Ohtsuka studied the total oxidation of monometallic and bimetallic $\mathrm{Pt}, \mathrm{Pd}$ and $\mathrm{Ir}$ catalysts supported on zirconia [22]. The activity and stability of the monometallic catalysts decreased in the order of $\mathrm{Pd}>\mathrm{Pt}>\mathrm{Ir}$ catalysts, however bimetallic $\mathrm{Ir}-\mathrm{Pt} / \mathrm{ZrO} \mathrm{Z}_{2}$ showed the best activity and low deactivation. Santos et al. investigated the total oxidation of toluene on $\mathrm{TiO}_{2}$ supported $\mathrm{Pt}, \mathrm{Pd}, \mathrm{Ir}, \mathrm{Rh}$ and Au catalysts. Highly dispersed particles on the support offered activities for total oxidation of toluene in the order of $\mathrm{Pt}$ $>\mathrm{Pd}>\mathrm{Rh}, \mathrm{Ir}>\mathrm{Au}[23]$.

The present study tries to fill the gap in the literature regarding supported iridium catalysts for total oxidation of VOCs, providing fundamental understanding of the effect of a number of parameters, such as particle size, reducibility of the $\mathrm{IrOx}$ species and the Ir oxidation state on the VOC oxidation activity. The study also provides mechanistic information about the structure sensitive nature of the total oxidation of propane. For this aim, silica has been selected as a support based on its negligible reactivity under the study reaction conditions and the weak silica-iridium interactions. In this way the results obtained can be assigned to the characteristics of iridium species. Similarly, iridium acetylacetonate has been used as metal precursor to avoid the presence of chloride ions, known to be detrimental in the catalytic activity. 


\section{Experimental}

Synthesis

The catalysts were prepared by incipient wetness impregnation using chloride-ion free iridium acetylacetonate, $\operatorname{Ir}(\mathrm{AcAc})_{3}($ Sigma Aldrich, >99\%) dissolved in toluene (Sigma Aldrich >99.8\%). The amount of noble metal was kept constant at $2 \mathrm{wt}$. \% for every catalyst. $\mathrm{SiO}_{2}$ Degussa Aerosil 200 was used as a support, calcined at $800^{\circ} \mathrm{C}$ for $2 \mathrm{~h}$ $\left(\mathrm{S}_{\mathrm{BET}}=181 \mathrm{~m}^{2} \mathrm{~g}^{-1}\right)$ to remove possible impurities and $\mathrm{OH}$ groups. After impregnation the catalysts were dried at $55^{\circ} \mathrm{C}$ for several hours, dried overnight at $120^{\circ} \mathrm{C}$ and finally calcined in air for two hours at temperatures between $350^{\circ} \mathrm{C}$ and $750^{\circ} \mathrm{C}$. Table 1 shows a summary of the iridium samples synthesized.

For comparison catalysts with $\mathrm{Pd}$ and $\mathrm{Pt}(2 \mathrm{wt} . \%)$ on silica were also synthesized by the same method (incipient wetness impregnation) using $\operatorname{Pt}(\mathrm{AcAc})_{2}$ and $\operatorname{Pd}(\mathrm{AcAc})_{2}$ salts (all Sigma Aldrich, >99\%), respectively. The catalysts were calcined in air for two hours at $350^{\circ} \mathrm{C}$.

\section{Characterisation techniques}

The catalysts were characterized by powder X-ray diffraction (XRD) using a D8 Advanced A25 by Bruker with a monochromatic CuKa1 radiation operated at $40 \mathrm{kV}$ and $40 \mathrm{~mA}$. Crystal phases were identified using diffraction data gained from literature via the American Mineralogist Crystal Structure Database [24].

TEM, HRTEM, SAED and EDX were performed using a FEI Field Emission gun Tecnai G2 F20 S-TWIN microscope operated at $200 \mathrm{kV}$. Morphological and structural characterizations were gained from TEM and HRTEM images. The lattice parameters were calculated via Fourier transformation from HRTEM images. Histograms and mean 
particle diameters were calculated from 100 to 400 measurements of the particle size in TEM and HRTEM images. Energy dispersive X-ray spectroscopy (EDX) in nanoprobe mode was to prove the investigated particle consists of the active metal. As in previous studies, the samples were prepared by sonication in ethanol and deposition of the solution onto a holey-carbon film supported on a copper grid followed by drying.

CO pulse chemisorption analyses were carried out using a Micromeritics Autochem 2920 rig under cryogenic conditions as in [25]. For analysis of the results, a stoichiometric coordination of two CO molecules per surface iridium site was assumed. Successive temperature programmed reduction, oxidation and reduction (TPR/TPO/TPR) analyses were also carried out in a Micromeritics Autochem 2920 instrument equipped with a thermal conductivity detector. The first reduction step was

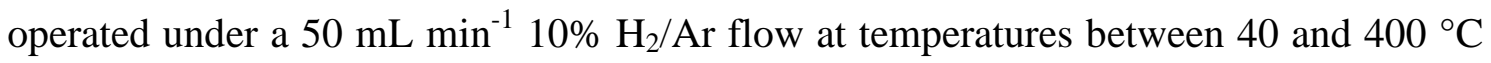
for $30 \mathrm{~min}$, with a heating rate of $20^{\circ} \mathrm{C} \mathrm{min}^{-1}$. Then, the sample was cold down to $40^{\circ} \mathrm{C}$ under He atmosphere. After stabilization, the oxidation step was carried out under a 50 $\mathrm{mL} \min ^{-1} 5 \% \mathrm{O}_{2} / \mathrm{He}$ flow at temperatures between 40 and $400{ }^{\circ} \mathrm{C}$ for $30 \mathrm{~min}$, with a heating rate of $20{ }^{\circ} \mathrm{C} \mathrm{min}^{-1}$. Following, the sample was cold down to $40^{\circ} \mathrm{C}$ under $\mathrm{Ar}$ atmosphere. Finally, the second reduction step was performed under the same conditions than the first reduction step.

The specific surface area of the catalysts was determined from nitrogen adsorption desorption isotherms at $-196^{\circ} \mathrm{C}$. A Micromeritics ASAP-2020 automated analyzer was used. Prior to the analyses the catalysts were degassed at $80^{\circ} \mathrm{C}$ for $5 \mathrm{~h}$ and $10^{-6}$ Torr. The Brunauer-Emmett-Teller (BET) model was used to calculate the surface areas.

X-ray photoelectron spectroscopy (XPS) measurements were made on a Kratos Axis ultra DLD photoelectron spectrometer using a non-monochromatized $\mathrm{Mg} \mathrm{K} \alpha \mathrm{X}$-ray 
source $(\mathrm{h} v=1253.6 \mathrm{eV})$. An analyser pass energy of $50 \mathrm{eV}$ was used for survey scans and $20 \mathrm{eV}$ for detailed scans. Binding energies were referenced to the $\mathrm{C} 1 \mathrm{~s}$ peak from adventitious carbonaceous contamination, assumed to have a binding energy of 284.8 eV. XPS data were analysed using CasaXPS software. All the peaks of the corrected spectra were fitted with a Gaussian-Lorentzian shape function to peak fit the data. Iterations were performed using the Marquardt method. Relative standard deviations were always lower than $1.5 \%$.

\section{$\underline{\text { Catalytic tests }}$}

The catalytic behaviour was studied using $100 \mathrm{mg}$ of the catalyst for total oxidation of alkanes. The catalyst was sieved to a grain size of $0.3-0.75 \mathrm{~mm}$ and loaded into a quartz tube micro reactor with an inner diameter of seven millimeters. When only one alkane was tested, the feed gas consisted of $0.8 \%$ vol. alkane (propane, ethane or methane), $19.8 \%$ vol. oxygen and $79.4 \%$ vol. helium to mimic the oxygen content in air. When a mixture of alkanes was used (either methane/ethane or ethane/propane) the feed gas consisted of $1.6 \%$ vol. of the mixture of alkanes (with a 50/50 vol. ratio), $19.7 \%$ vol. oxygen and $78.7 \%$ vol. helium The total volume flow was set to $50 \mathrm{ml} / \mathrm{min}$. The reactor was surrounded with a temperature-controlled oven and the temperature inside the fixed catalyst bed was measured using a thermocouple. During the catalytic tests, the temperature of the catalyst bed was raised from $150^{\circ} \mathrm{C}$ to the temperature at which $100 \%$ conversion was achieved in steps of $25^{\circ} \mathrm{C}$ and was hold for 20 minutes at every step prior to the measurement to gain stationary state. Two analyses were made at each temperature and the results averaged. The outlet gas was analyzed by injections into a Hewlet-Packard gas chromatograph equipped with a Carbosieve-S and a Porapak Q column. Once the reaction was completed, the oven was switched off and the catalyst was allowed to slowly cool down inside a stream of pure helium. 
For stability studies, the catalyst was held at temperatures of moderate conversions and the development of the conversion versus time on stream was monitored.

\section{Results}

\section{$\underline{3.1 \text { Catalytic results }}$}

The total oxidation of propane was used as model molecule to understand the effect of catalytic parameters in iridium-based systems. To ensure that the catalytic activity is uniquely associated to the presence of iridium, the activity of the silica support (AerosilDegussa calcined at $800^{\circ} \mathrm{C}$ ) was confirmed negligible in the interval of reaction temperatures studied (until $500^{\circ} \mathrm{C}$ ).

In the presence of iridium (see characteristics in Table 1), the only reaction products observed in all experiments were $\mathrm{CO}_{2}$ and $\mathrm{H}_{2} \mathrm{O}$. No $\mathrm{CO}$, oxygenated compounds or other hydrocarbons were detected and the C-balance was found in all cases to be $100 \pm 5 \%$.

Table 1. Characteristics of the Iridium supported on silica catalysts synthesized (surface area and particle size)

\begin{tabular}{cccccc}
\hline Catalyst & $\begin{array}{c}\text { Ir-loading } \\
\text { Wt.\% }\end{array}$ & $\begin{array}{c}\text { Calcination } \\
\text { Temperature }\left({ }^{\circ} \mathrm{C}\right)\end{array}$ & $\begin{array}{c}\text { Surface area } \\
\left(\mathrm{m}^{2} \mathrm{~g}^{-1}\right)\end{array}$ & $\begin{array}{c}\text { Dispersion } \\
\operatorname{Ir}(\%)\end{array}$ & $\begin{array}{c}\text { Particle size } \\
(\mathrm{nm})^{\mathrm{a}}\end{array}$ \\
\hline Ir/Si350 & 2.0 & 350 & 174 & 21.4 & 5.2 \\
Ir/Si450 & 2.0 & 450 & 173 & 14.1 & 7.8 \\
Ir/Si550 & 2.0 & 550 & 177 & 8.1 & 13.7 \\
Ir/Si650 & 2.0 & 650 & 171 & 6.4 & 17.2 \\
Ir/Si750 & 2.0 & 750 & 168 & 4.2 & 26.7 \\
\hline
\end{tabular}

${ }^{\mathrm{a}}$ IrOx particle size estimated by CO chemisorption assuming a CO:Ir stoichiometric factor of 2 . 
The effect of the calcination temperature of the catalysts on the resulting oxidation activity was studied. Figure 1 shows the evolution of the propane conversion with the reaction temperature for $2 \mathrm{wt} . \% \mathrm{Ir} / \mathrm{SiO}_{2}$ catalysts calcined at temperatures between 350 and $750^{\circ} \mathrm{C}$. The conversion curves present a similar sigmoidal shape for all the catalysts, shifting to higher temperatures (the catalytic activity decreases at a given temperature) when the calcination temperature increases. Thus, that catalyst heat-treated at $350^{\circ} \mathrm{C}$ is the most active whereas that treated at $750^{\circ} \mathrm{C}$ presents the lowest reactivity for a given temperature. The catalyst heat-treated at $350^{\circ} \mathrm{C}$ presents $50 \%$ conversion at $225^{\circ} \mathrm{C}$ and a total conversion at a temperature as low as $325^{\circ} \mathrm{C}$. In contrast, the sample heat-treated at $750^{\circ} \mathrm{C}$ requires a reaction temperature of $450^{\circ} \mathrm{C}$ for obtaining $100 \%$ propane conversion.

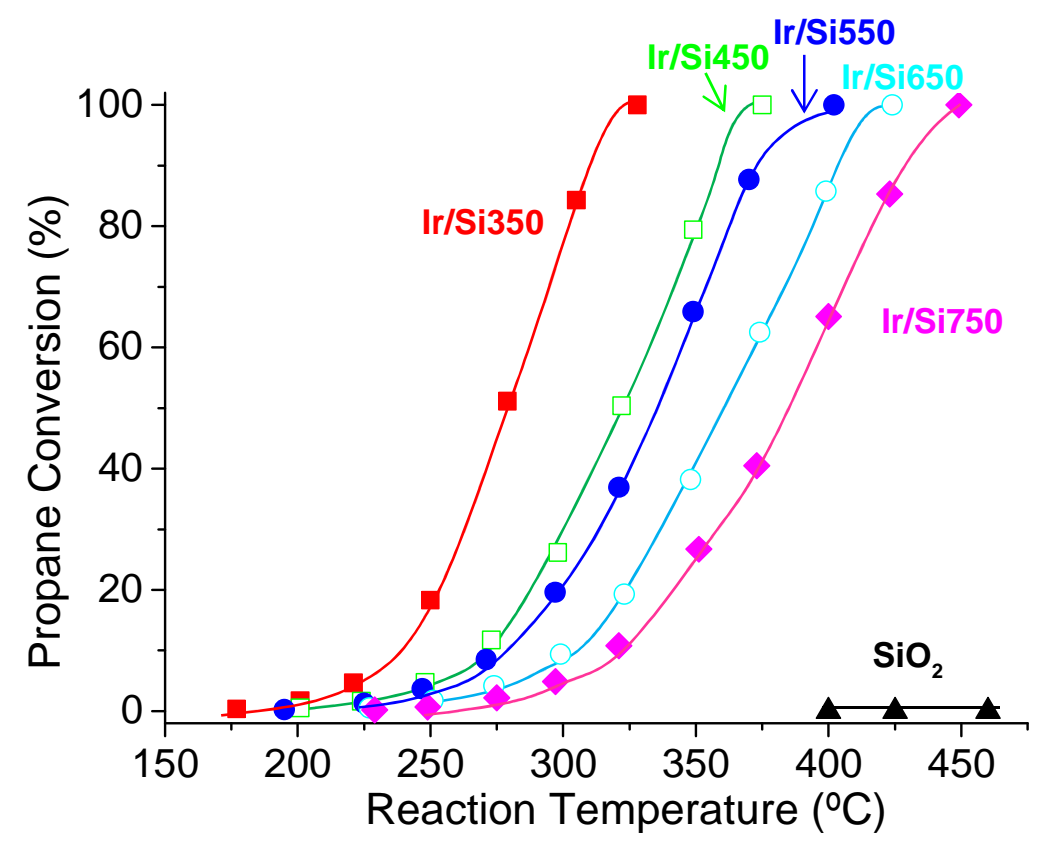

Figure 1. Variation of the propane conversion with the reaction temperature for $2 \mathrm{wt} . \%$ iridium catalysts supported on silica. Note: Catalyst calcined at $350^{\circ} \mathrm{C}(\mathbf{\square}), 450^{\circ} \mathrm{C}(\square)$, $550^{\circ} \mathrm{C}(\bullet), 650^{\circ} \mathrm{C}(\circ), 750^{\circ} \mathrm{C}(\bullet)$. Pure Support $(\Delta)$. Reaction conditions in the experimental section. 
In order to understand the reactivity of iridium-based catalysts compared to other noble metals, catalysts containing $\mathrm{Pt}, \mathrm{Pd}$ and $\mathrm{Au}$ were prepared $(2$ wt.\% of metal and calcination temperature of $350^{\circ} \mathrm{C}$ ) and tested under the same conditions. Platinum resulted to be the most active catalyst (Figure S1, Supporting Information) followed by that of iridium. Surprisingly, the iridium sample showed a higher reactivity than the palladium catalyst. Finally, gold catalyst was shown as the least active.

To get further understanding of the nature of the catalyst, a stability study of the $2 \mathrm{wt} . \%$ $\mathrm{Ir} / \mathrm{SiO}_{2}$ catalyst reduced at $350^{\circ} \mathrm{C}$ was carried out. For this, fresh $\mathrm{Ir} / \mathrm{Si} 350$ catalyst was tested at a fixed temperature of $275^{\circ} \mathrm{C}$ for $5-6$ hours. The initial conversion is $c a .55 \%$ however, the conversion dropped with time, reaching a steady-state conversion of $c a$. $35 \%$ after 3.5-4 hours of reaction (Figure 2). In Figure S2 (Supporting Information), a second catalytic cycle for $\operatorname{Ir} / \mathrm{Si} 350$ is shown. As can be seen, the activity is lower in the second cycle and the light-off curve is shifted towards higher temperatures (ca. $12^{\circ} \mathrm{C}$ ). Interestingly, similar levels of conversion are achieved with the used $\mathrm{Ir} / \mathrm{Si} 350$ catalyst after a thermal cycle up to $325^{\circ} \mathrm{C}$ (as in Figure 1). Contrary to this, the fresh catalysts heat-treated at higher temperature $\left(>450^{\circ} \mathrm{C}\right)$ show a stable conversion over time (Figure 3) with no further deactivation taking place. 


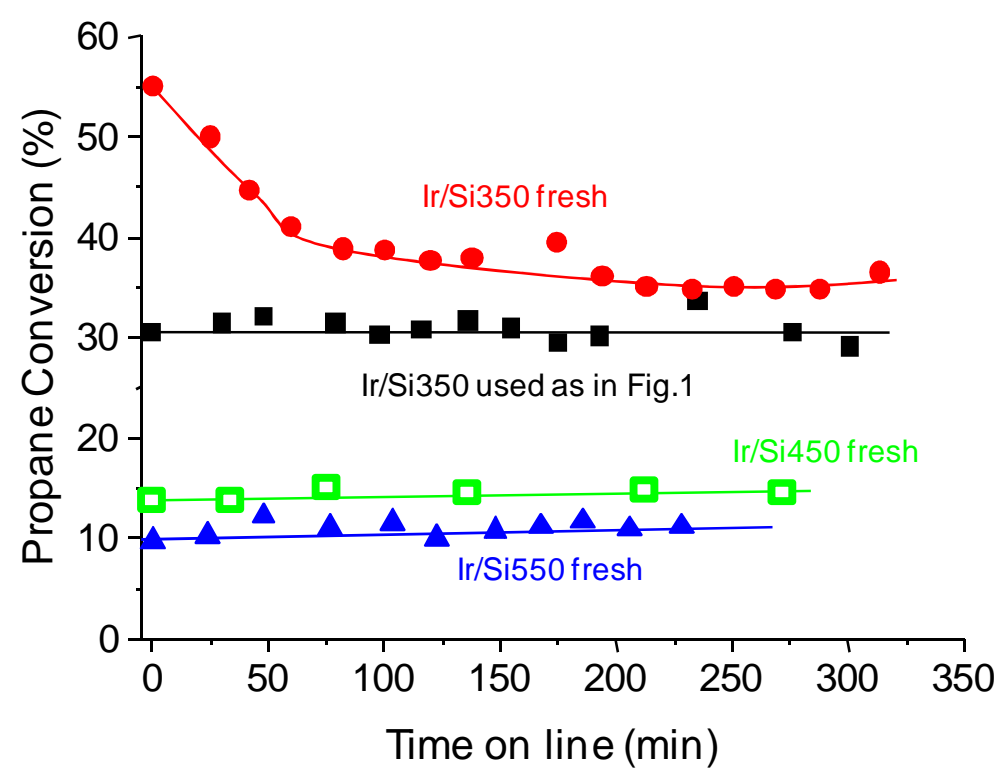

Figure 2. Evolution of the propane conversion with the time using 2 wt.\% $\mathrm{Ir} / \mathrm{SiO}_{2}$ catalysts calcined at $350^{\circ} \mathrm{C}(\bullet), 450^{\circ} \mathrm{C}(\square)$ and $550^{\circ} \mathrm{C}(\boldsymbol{\Delta})$. (a) represents the $\mathrm{Ir} / \mathrm{Si} 350$ catalyst after the experiment in Figure 1. Notes: Reaction temperature: $275^{\circ} \mathrm{C}$ and remaining reaction conditions as shown in the experimental section.

Apart from propane, the elimination by total oxidation of other short chain alkanes were also tested (Figure $3 \mathrm{~A}$ ) using the $\mathrm{Ir} / \mathrm{Si} 550$ catalyst. The catalyst calcined at $550^{\circ} \mathrm{C}$ has been selected for this study because methane presents low reactivity and we wanted to avoid the use of reaction temperatures over those of calcination. As can be observed in Figure 3, and as it was expected, the longer the chain of the alkane the higher is the reactivity. Then, to achieve $20 \%$ conversion 350,335 and $295^{\circ} \mathrm{C}$ were required for methane, ethane and propane, respectively. For 90\% conversion, the temperatures required were $427\left(\mathrm{C}_{1}\right), 412\left(\mathrm{C}_{2}\right)$ and $370^{\circ} \mathrm{C}\left(\mathrm{C}_{3}\right)$. It is especially noteworthy the relatively high activity for methane elimination and also the scarce differences observed between ethane and methane in spite of the presence of $\mathrm{C}-\mathrm{H}$ bonds with different stability as ethane presents primary $\mathrm{C}-\mathrm{H}$ bonds whereas methane only methyl $\mathrm{C}-\mathrm{H}$ bonds with high bond energies. Stability in methane oxidation was checked by running a second and third catalytic cycle and no differences were observed compared to the first run. 
Finally, we also wanted to check the performance of $\mathrm{Ir} / \mathrm{Si} 550$ catalyst to remove mixtures of short chain alkanes. Then, the catalytic performance of the catalyst when the hydrocarbons are present as a mixture has been compared to the performance when they are fed alone. Feeding simultaneously methane and ethane at $375^{\circ} \mathrm{C}$ (Figure $3 \mathrm{~B}$ ) it has been observed that methane conversion (ca. 42\%) is just slightly lower than that conversion obtained using methane alone (ca. 45\%). Similarly, feeding the methane/ethane mixture the ethane conversion obtained (ca. 48\%) is only a bit lower than that alone (ca. 51\%). In Figure 3C it is shown the propane and ethane conversions at $350^{\circ} \mathrm{C}$ when they are mixed or when they are alone. The differences observed for both alkanes are scarce. Therefore, there has not been observed a deleterious effect in catalytic activity when alkanes are mixed. 


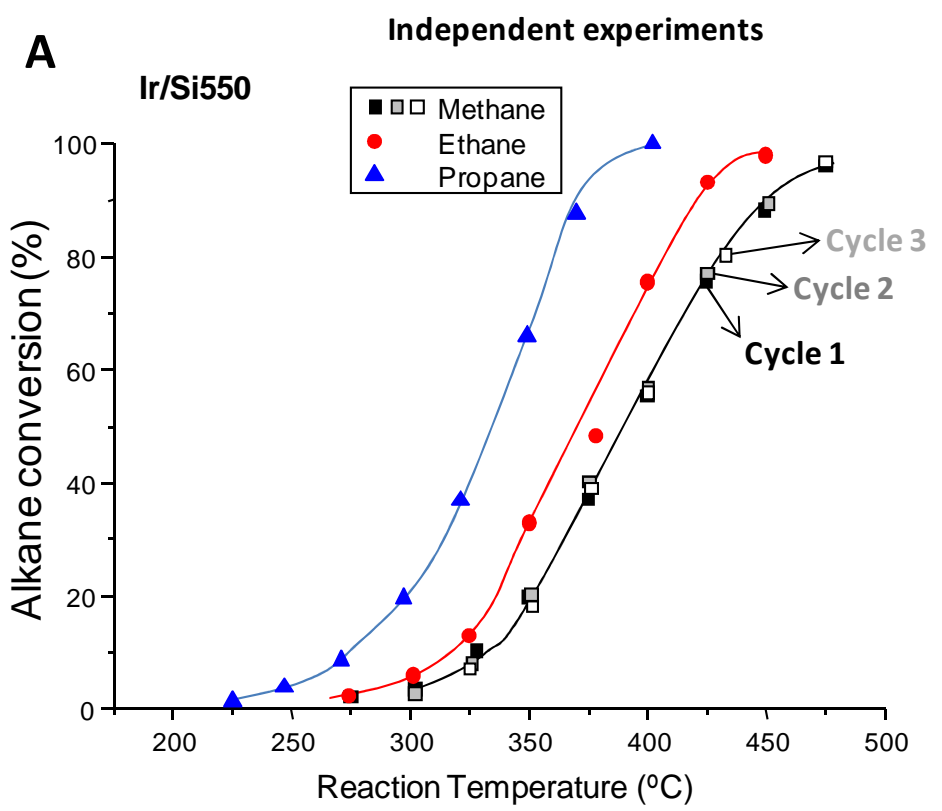

B

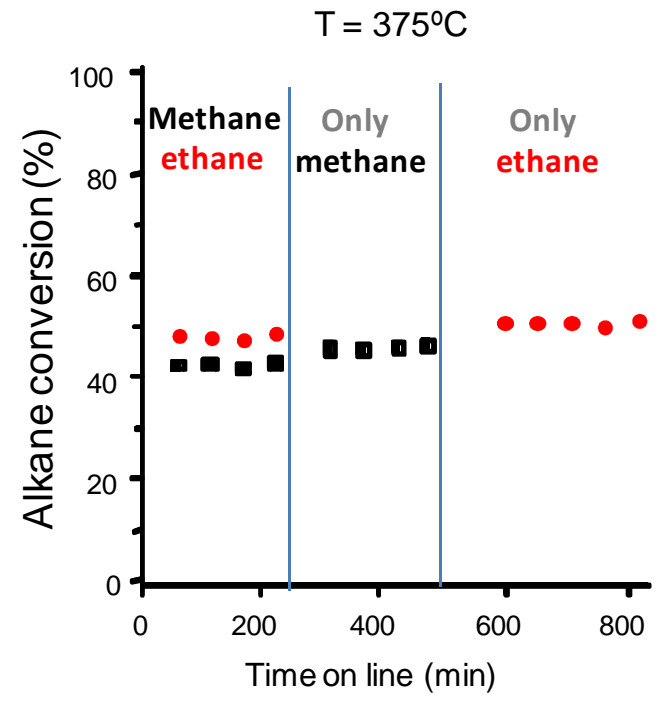

C

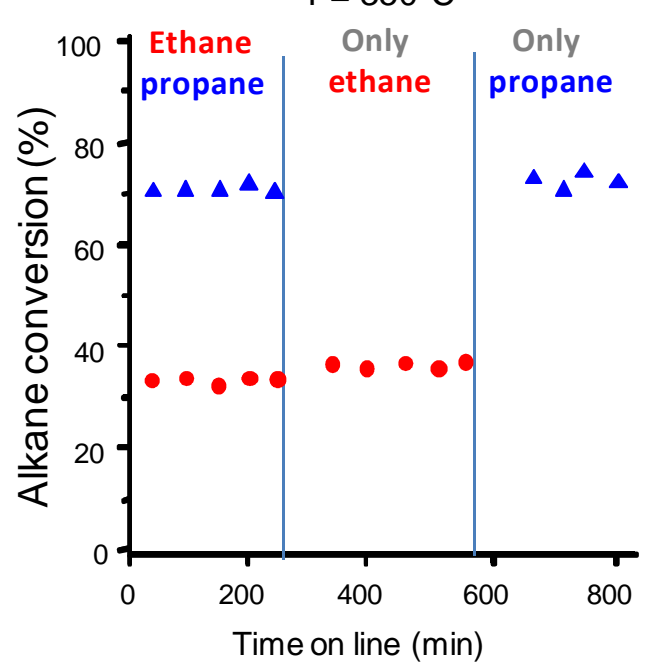

Figure 3. Evolution of the alkane conversion with the reaction time using 2 wt.\% $\mathrm{Ir} / \mathrm{SiO}_{2}$ catalyst calcined at $550^{\circ} \mathrm{C}$. Fig. 3A: Comparison of alkanes, independent experiments. Fig. 3B: Evolution of methane and/or ethane conversions with the time on line when either fed together or fed alone. Fig. 3C: Evolution of ethane and/or propane conversions with the time on line when either fed together or fed alone. Symbols: ( $\mathbf{A})$ propane, $(\bullet)$ ethane, $(\bullet)$ methane.

\subsection{Characterization of the catalysts}

A small decrease on the surface area of the silica support was observed after impregnation of iridium followed by calcination. Pure silica support presents a surface area of $181 \mathrm{~m}^{2} \mathrm{~g}^{-1}$, which slightly decreases to $c a .170 \mathrm{~m}^{2} \mathrm{~g}^{-1}$ when iridium is added. 
XRD patterns of the iridium catalysts are shown in Figure S3. All the catalysts of the $\mathrm{Ir} / \mathrm{SiO}_{2}$ series show amorphous patterns, corresponding to the silica support, plus the characteristic diffraction peaks of $\mathrm{IrO}_{2}$ (JCPDS: 43-1019). The intensity of the iridium oxide peaks as well as the crystallinity increase when the calcination temperature increases. No metallic iridium or other iridium containing phases could be observed.

A detailed transmission electronic microscopy study was also conducted on the iridium/silica catalysts (Figures 4 and S4). Figures 4a and 4b show representative TEM images of the Ir/Si350 catalyst. It can be seen that most of the iridium oxide particles are highly dispersed and are spherical showing a good contrast with the silica support. The histogram determined by measuring 430 particles under the assumption of spherical like units (Figure 5) shows an average particle diameter of $4.8 \mathrm{~nm}$. Most of the particles observed are in the 2 to $4 \mathrm{~nm}$ range, with $75 \%$ of the particles analysed being smaller than $6 \mathrm{~nm}$, although there are few larger particles with sizes up to $15 \mathrm{~nm}$. 


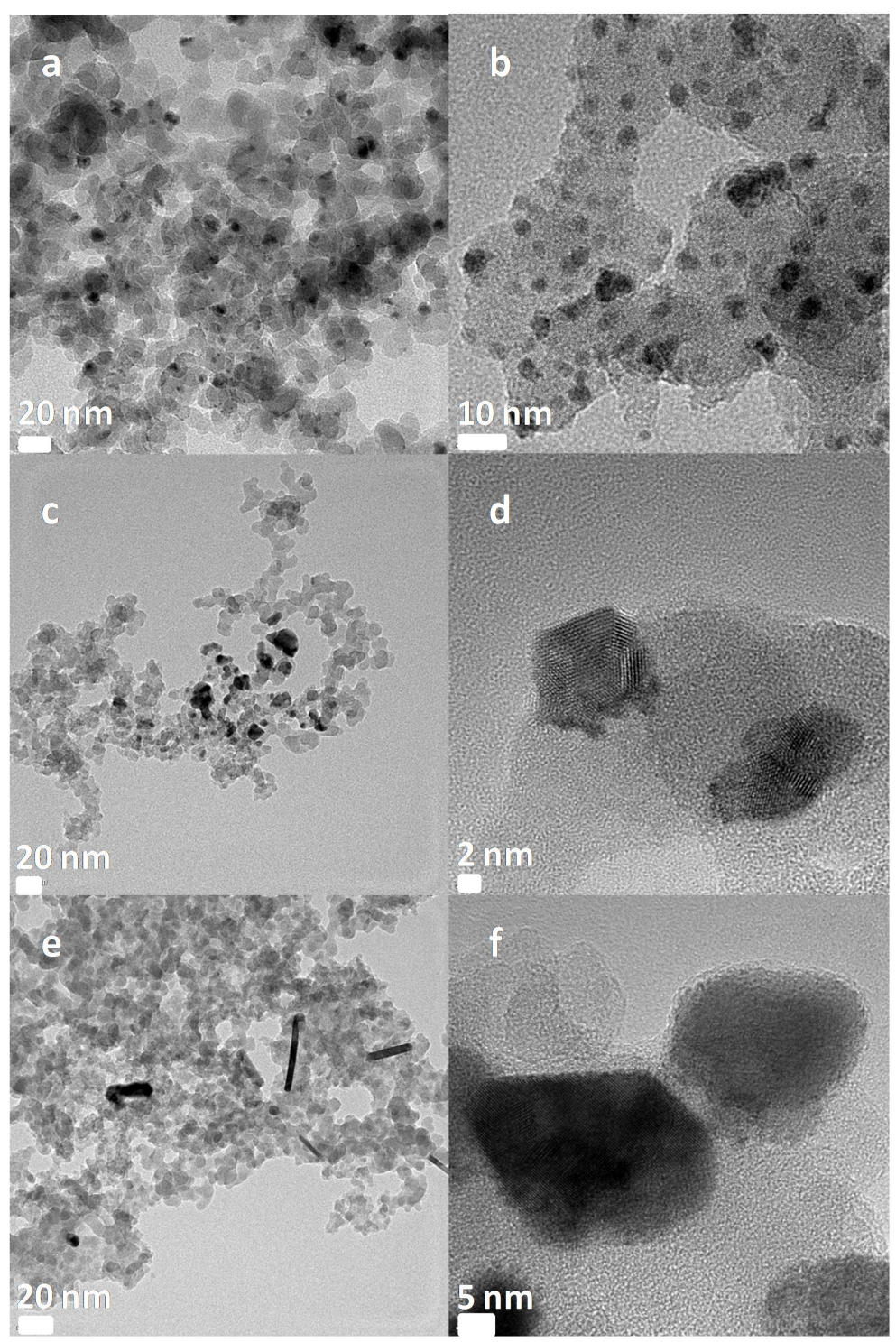

Figure 4. TEM images for $\operatorname{Ir} / \operatorname{Si} 350(a, b), \operatorname{Ir} / \operatorname{Si} 550(c, d)$ and $\operatorname{Ir} / \operatorname{Si} 750(e, f)$ catalysts.

In case of the Ir/Si550 catalyst, in addition to the spherical particles, accounting for ca. 90\%, elongated particles are also observed (Figures $4 \mathrm{c}$ and $4 \mathrm{~d}$ ). In this case, both morphologies have been analysed separately. The particle size distribution calculated by measuring 220 spherical and pseudo-spherical particle diameters is presented in Figure 5 showing an average spherical particle diameter of $9.0 \mathrm{~nm}$. The analysis of 29 elongated particles resulted in an average length of $66.7 \mathrm{~nm}$ and an average diameter (thickness) of $8.4 \mathrm{~nm}$. The rod shaped particles vary randomly in length but show a 
Gaussian like distribution in thickness (although with a small statistically sample size). As in the case of the $\mathrm{Ir} / \mathrm{Si} 550$ catalyst, in the $\mathrm{Ir} / \mathrm{Si} 750$ catalyst (Figures $4 \mathrm{e}$ and $4 \mathrm{f}$ ) spherical and elongated particles are present with the former ones accounting for ca. $70 \%$ of the total iridium oxide particles. The histogram calculated by measuring 138 spherical particle diameters is shown in Figure 5 and the average spherical particle diameter resulted to be $19.7 \mathrm{~nm}$. The analysis of 70 rod like particles resulted in an average length of $56.9 \mathrm{~nm}$ and an average diameter (thickness) of $12.2 \mathrm{~nm}$. The rod shaped particles offer a Gaussian like distribution in both length and thickness.

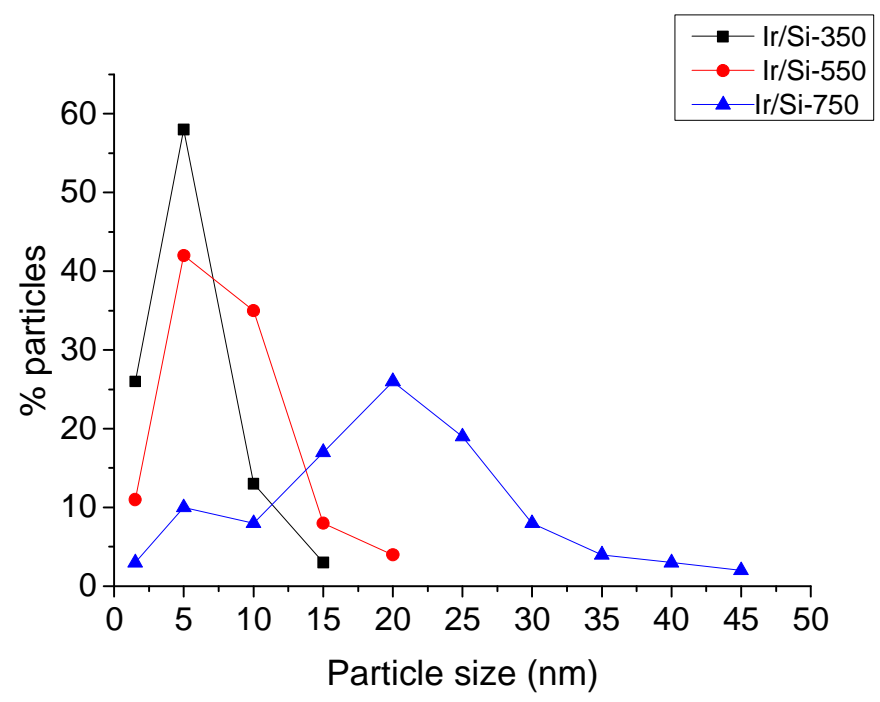

Figure 5. Particle size distribution determined by TEM of the fresh $\mathrm{Ir} / \mathrm{Si} 350, \mathrm{Ir} / \mathrm{Si} 550$ and $\mathrm{Ir} / \mathrm{Si} 750$ catalysts. Note: Only spherical and pseudo-spherical particles are considered.

In order to have a close look and to identify the nature of nanoparticles, HRTEM measurements were carried out (Figure 6). HRTEM images and Fast Fourier Transform (FFT) performed on the selected nanoparticles clearly exhibited the crystalline nature with defined fringes. In the case of the Ir/Si550 sample (Figure 6b), the measured d(hkl) determined from direct measurement of spacing in between the crystal fringes were about 3.21, 2.58 and $1.59 \AA$, attributed to the lattice spacing of (110), (101) and (220) family planes of $\mathrm{IrO}_{2}$ in its tetragonal structure respectively (JCPDS 01-086-0330). 
Similarly, in the catalyst calcined at the highest temperature, Ir/Si750, only family planes of $\mathrm{IrO}_{2}$ in its tetragonal structure were observed. However, in the case of the catalyst calcined at the lowest temperature, Ir/Si350, different $\mathrm{d}(\mathrm{hkl})$ were obtained corresponding to two different types of nanoparticles; in addition to those corresponding to $\mathrm{IrO}_{2}$ which are the majority, another measured interplanar distance [d(hkl)] about 2.2 $\AA$ (Figure 6a) was observed, which could be attributed to the (111) lattice spacing of metallic Ir in its cubic phase structure in good agreement with the data in reference: JCPDS 046-1044. These metallic Ir nanoparticles are situated in close contact to the $\mathrm{IrO}_{2}$ nanoparticles.

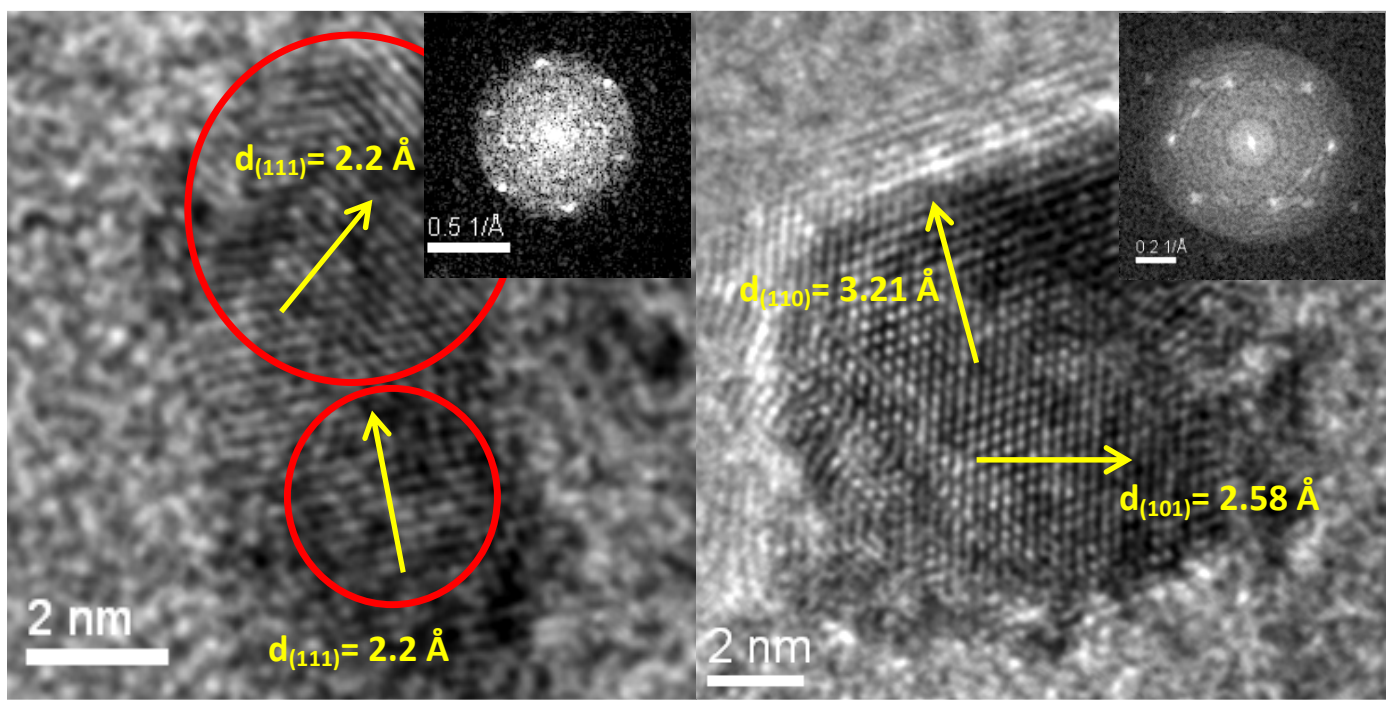

Figure 6. HRTEM images of iridium nanoparticles in fresh (left) $\mathrm{Ir} / \mathrm{Si} 350$ and (right) $\mathrm{Ir} / \mathrm{Si} 550$ catalysts. Inset figures are their corresponding digital electron diffraction pattern (FFT), on the selected nanoparticles.

Interestingly, the used Ir/Si350 catalyst after a reaction cycle (Figure S5) did not show spacing corresponding to metallic Ir and only those of $\mathrm{IrO}_{2}$ phase could be observed, suggesting the oxidation and further sintering of the metallic Ir nanoparticles into $\mathrm{IrO}_{2}$ with a larger particle size in line with TPR data. It must be noted that no spacing 
corresponding to the iridium salt employed in the preparation method of these catalysts (Ir acetyl acetonate) has been detected in any of the studied catalysts. Table S1 summarizes the measured $\mathrm{d}(\mathrm{hkl})$ of the different samples (fresh and used Ir/Si350, Ir/Si550 and Ir/Si750 catalysts) in comparison with the data cited in JCPDS database: file 046-1044 and 01-086-0330 corresponding to cubic Ir and tetragonal $\mathrm{IrO}_{2}$, respectively.

TEM-EDAX measurements were also conducted on the catalysts. Figure 7 shows a localized EDX spectrum of an individual nanoparticle on the fresh $\mathrm{Ir} / \mathrm{Si} 550$ sample where no significant amount of other elements apart from $\mathrm{Ir}, \mathrm{Si}$ and $\mathrm{O}$ (from the catalyst) and $\mathrm{Cu}$ and $\mathrm{C}$ (from the grids) were detected. EDX-mapping showed a good distribution of iridium (as metallic $\mathrm{Ir}$ and/or $\mathrm{IrO}_{2}$ nanoparticles) on the silica matrix. Moreover, it was observed that iridium is mainly present in the areas of the images with high contrast (dark points) in the catalyst calcined at $550^{\circ} \mathrm{C}$ ( $\left.\mathrm{Ir} / \mathrm{Si}-550\right)$ whereas is more dispersed in the Ir/Si-350 catalyst. 

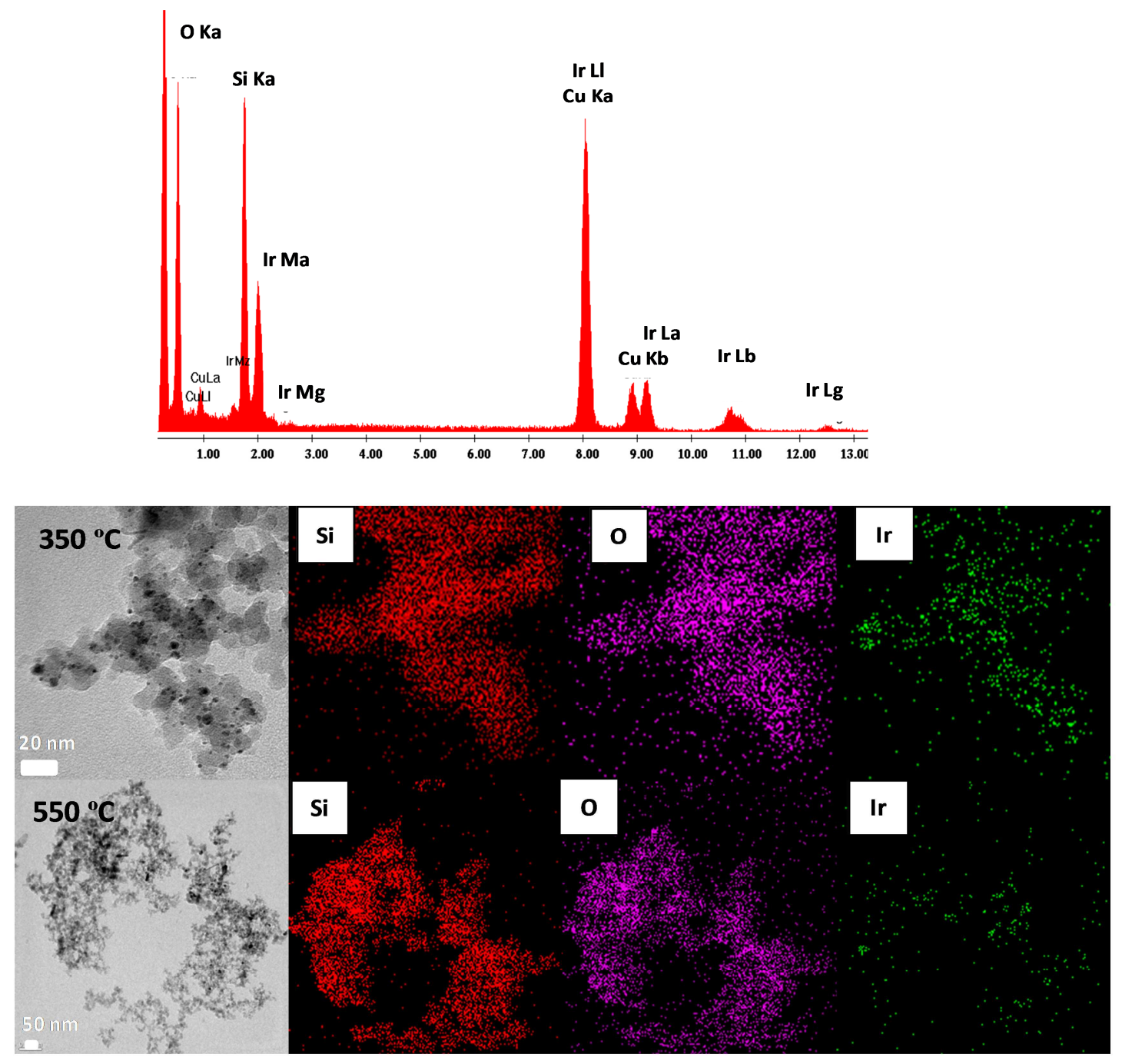

Figure 7. EDX spectrum and EDX-mapping of the fresh Ir/Si350 and Ir/Si550 samples.

In order to get an additional estimation of the iridium particle size in the catalysts, chemisorption techniques were used after in-situ $\mathrm{H}_{2}$ treatment. The use of oxygen as chemisorption molecule is not possible as the oxidation of $\mathrm{Ir}$ to $\mathrm{IrO}_{2}$ occurs at temperatures close to the ambient temperature [30]. In fact, if some of the oxides of the main noble metals are compared (Ir, Pt, Pd, Rh), iridium presents the highest Metal-O bond energy and consequently the formation of surface iridium-oxygen species is highly favoured [31]. Alternatively, $\mathrm{H}_{2}$ and $\mathrm{CO}$ molecules can be used, although they present some inaccuracies. For example, the $\mathrm{H}_{2}: \mathrm{Ir}$ stoichiometric varies with the size of the iridium particles. $\mathrm{A}_{2}$ :Ir stoichiometric factor of 2.6 has been found for small particle 
size and high dispersions (ca. 0.9) while a value of 2.0 is more appropriate for bigger particles size and lower dispersions (ca. 0.5) as estimated by Kip and co-workers [3233]. In the present article we have used $\mathrm{CO}$ chemisorption which, although has also similar limitations than the $\mathrm{H}_{2}$ chemisorption, provides reasonable estimations of the Ir dispersions [34]. For this, a CO:Ir stoichiometric factor of 2 and spherical shapes have been assumed [35] (Table 1). For a given support the higher the calcination temperature the higher is the particle size observed, according to an expected sintering of iridium nanoparticles at high temperature. Thus, the mean particle size for the catalyst heattreated at $350^{\circ} \mathrm{C}$ is ca. $5 \mathrm{~nm}$ whereas that treated at $750^{\circ} \mathrm{C}$ is ca. $27 \mathrm{~nm}$. It is worth to point out that the values obtained are roughly similar to those obtained by microscopy.
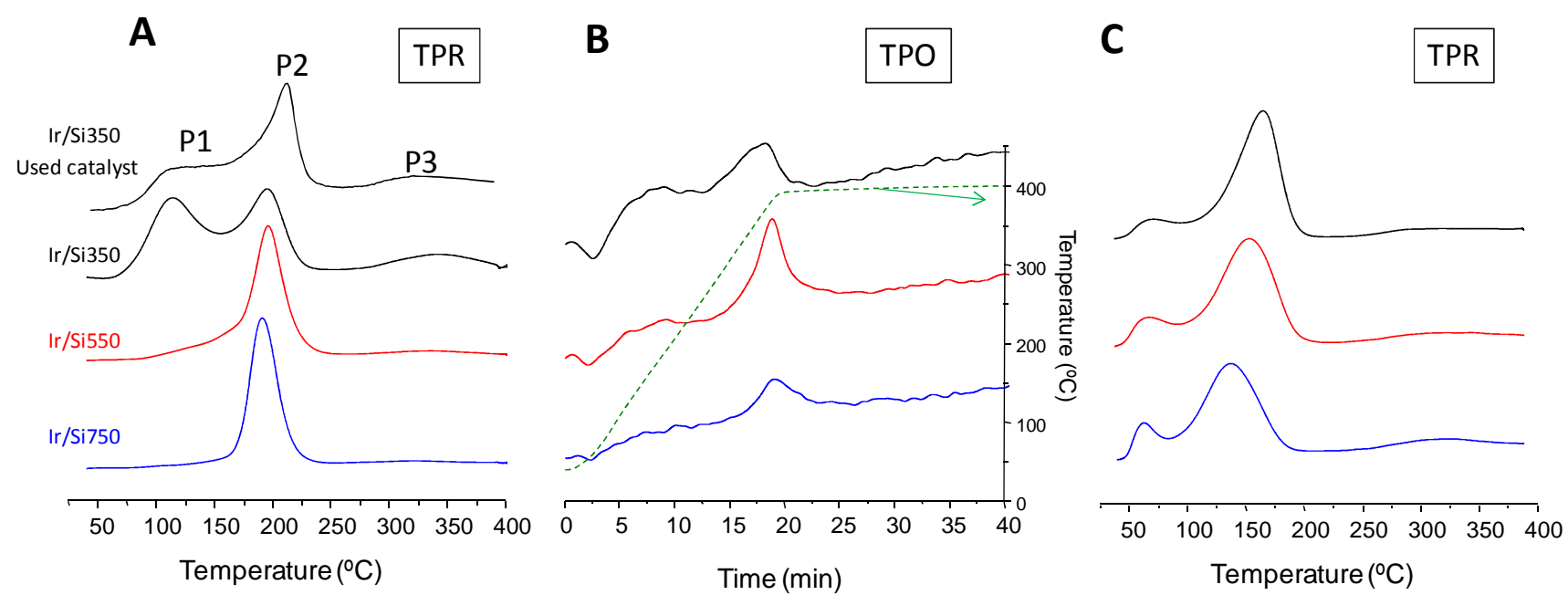

Figure 8. TPR/TPO/TPR profiles of fresh $\mathrm{Ir} / \mathrm{Si} 350, \mathrm{Ir} / \mathrm{Si} 550$ and $\mathrm{Ir} / \mathrm{Si} 750$ catalysts. Notes: First TPR cycle (Fig. 8A), TPO (Fig. 8B), Second TPR cycle (Fig. 8C). Catalysts: Ir/Si350 (in black), Ir/Si550 (in red), Ir/Si750 (in blue). In Fig. 8A it is also shown the TPR profile of $\mathrm{Ir} / \mathrm{Si} 350$ catalyst used in reaction after the experiment of Figure 2.

Temperature programmed reduction experiments were undertaken to study the reducibility of the iridium/ $/ \mathrm{SiO}_{2}$ samples (Figure 8A). Various reduction peaks due to the presence of $\mathrm{IrO}_{2}$ species with different reducibility and likely crystallite size could be observed, in line with XRD and microscopy data. Three bands have been observed in all 
the catalysts: i) the main one (P2) presents a maximum at ca. $195^{\circ} \mathrm{C}$ likely related to crystalline $\mathrm{IrO}_{2}$, ii) a band (P1) corresponding to highly reducible species at $100-125^{\circ} \mathrm{C}$ and iii) a band (P3) with very low intensity at ca. $330^{\circ} \mathrm{C}$ which has been associated to the reduction of highly dispersed $\mathrm{IrO}_{2}$ species closely interacting with the support [26, 27]. The relative intensity of the bands clearly varies with the calcination temperature. Thus, the low temperature peak is very intense in $\mathrm{Ir} / \mathrm{Si} 350$ whereas in $\mathrm{Ir} / \mathrm{Si} 550$ presents low intensity and is almost absent in $\mathrm{Ir} / \mathrm{Si750}$. In line with microscopy data, the existence of tiny metallic Ir species in Ir/Si350 might explain the evolution of the lowtemperature hydrogen consumption peak since a spill-over mechanism of adsorbed atomic hydrogen from metallic $\mathrm{Ir}$ to those $\mathrm{IrO}_{2}$ nanoparticles in close contact could ease the reducibility of the $\mathrm{IrO}_{2}$ surface species. Interestingly, $\mathrm{Ir} / \mathrm{Si} 350$ is the most active catalyst, suggesting that these species could act as highly active sites for the alkane total oxidation. Then, it can be observed that the intensity of the low temperature band decreases with the calcination temperature in line with the decreased catalytic activity observed.

The TPR profile of the used Ir/Si350 catalyst (after experiments shown in Figures 1 and 3) shows important differences with that of the fresh Ir/Si350 catalyst. Importantly, the highly reducible species which reduces at $100-125^{\circ} \mathrm{C}$ in the fresh $\mathrm{Ir} / \mathrm{Si} 350$ catalyst decreases drastically in intensity in the used catalyst. Simultaneously, the hydrogen consumption associated to crystalline $\mathrm{IrO}_{2}$ increases and slightly shifts to higher temperature, pointing out that an oxidation and sintering of the metallic Ir sites with the $\mathrm{IrO}_{2}$ nanoparticles in close contact, is likely taking place during the catalytic reaction. It must be indicated that, unlike Ir/Si350, no appreciable differences were observed in the TPR profiles of the used $\mathrm{Ir} / \mathrm{Si} 550$ and $\mathrm{Ir} / \mathrm{Si} 750$ catalysts compared to the fresh catalysts. 
In the TPR experiments (Figure 8A) it was observed that for all the catalysts tested the hydrogen consumption approximately corresponded to the total reduction of $\mathrm{IrO}_{2}$ into metallic $\operatorname{Ir}\left(4.8 \mathrm{~cm}^{3} / \mathrm{g}_{\text {cat }}\right.$ experimental vs $5.08 \mathrm{~cm}^{3} / \mathrm{g}_{\text {cat }}$ theoretical $)$. In order to see the reoxidation capability of the catalysts, after the TPR assay, a temperature programmed oxidation (TPO) experiment was undertaken (Figure 8B). In the oxidation cycle (TPO) only a part of the metallic Ir was re-oxidized, the extent of the oxidation depending on the catalyst studied. Thus, the lower the calcination temperature the higher was the oxidation degree observed. Then 61,50 and $30 \%$ of the total Ir present after the first TPR experiment was oxidized into $\mathrm{IrO}_{2}$ for $\mathrm{Ir} / \mathrm{Si} 350$, Ir/Si550 and $\mathrm{Ir} / \mathrm{Si} 750$ catalysts respectively. Two different oxidation bands could be observed, one at ca. $150^{\circ} \mathrm{C}$ and a second one at ca. $400^{\circ} \mathrm{C}$, in the catalysts calcined at 350 and $550^{\circ} \mathrm{C}$ whereas in the catalyst calcined at $750^{\circ} \mathrm{C}$ only the band at ca. $400^{\circ} \mathrm{C}$ was detected. Moreover, in Ir/Si350 the intensity of the low temperature oxidation band is remarkably higher than in $\mathrm{Ir} / \mathrm{Si} 550$. Then, the re-oxidation capability seems to be inversely related to the calcination temperature of the catalyst.

Finally, a new TPR cycle was undertaken after the TPO experiment (Figure 8C). It was observed that the TPR profiles were very similar for all three catalysts and all the $\mathrm{IrO}_{2}$ formed after the TPO test was reduced again $\left(\mathrm{H}_{2}\right.$ consumptions of $2.9,2.5$ and 1.5 $\mathrm{cm}^{3} / \mathrm{g}_{\text {cat }}$ for Ir/Si350, Ir/Si550 and Ir/Si750 catalysts respectively). Interestingly, in the second reduction cycles the reduction took place at lower temperatures than in the first TPR cycle for all the catalysts which apparently suggest an improvement of the reducibility. We must indicate that these TPR/TPO/TPR experiments provide information about reducibility and re-oxidation of iridium sites although the conditions are largely different to those of reaction conditions. 
XPS was used to investigate the characteristics of the near surface of the catalysts

(Table 2 and Figure 9). In this way, the oxidation state of iridium as well as the relative amount of the elements of the catalysts has been estimated.

Table 2. XPS results of Ir-supported catalysts.

\begin{tabular}{|c|c|c|c|c|c|}
\hline & \multicolumn{2}{|c|}{$\mathrm{Ir} / \mathrm{Si}$ wt. } & \multirow{2}{*}{$\begin{array}{c}\mathrm{Si} \\
\text { Surface }\end{array}$} & \multirow{2}{*}{$\begin{array}{c}\operatorname{Ir}^{3+} / \mathrm{Ir}^{\mathrm{a}} \\
\text { Surface }(\%)\end{array}$} & \multirow{2}{*}{$\begin{array}{c}\operatorname{Ir}^{4+} / \operatorname{Ir}^{\mathrm{a}} \\
\text { Surface }(\%)\end{array}$} \\
\hline & Surface & Bulk & & & \\
\hline $\mathrm{Ir} / \mathrm{Si} 350$ & 0.06 & 0.04 & $100 \% \mathrm{Si}^{4+}$ & 83.0 & 16.1 \\
\hline $\mathrm{Ir} / \mathrm{Si} 350$ used & 0.06 & 0.04 & $100 \% \mathrm{Si}^{4+}$ & 84.8 & 15.2 \\
\hline $\mathrm{Ir} / \mathrm{Si} 450$ & 0.06 & 0.04 & $100 \% \mathrm{Si}^{4+}$ & 81.7 & 18.3 \\
\hline $\mathrm{Ir} / \mathrm{Si} 550$ & 0.06 & 0.04 & $100 \% \mathrm{Si}^{4+}$ & 79.5 & 20.5 \\
\hline $\mathrm{Ir} / \mathrm{Si} 650$ & 0.05 & 0.04 & $100 \% \mathrm{Si}^{4+}$ & 74.1 & 25.9 \\
\hline $\mathrm{Ir} / \mathrm{Si} 750$ & 0.04 & 0.04 & $100 \% \mathrm{Si}^{4+}$ & 68.4 & 31.6 \\
\hline
\end{tabular}

${ }^{\mathrm{a}}$ Metallic Ir was also reported.

Considering the Ir 4f core level (Figure 9A), all the samples present similar spectra and deconvolution pattern. There is a main Ir $4 \mathrm{f} 7 / 2$ peak located at around $61.4 \mathrm{eV}$ which can be assigned to $\mathrm{Ir}^{3+}$ species and a second $\mathrm{Ir} 4 \mathrm{f} 7 / 2$ peak located at around $63.3 \mathrm{eV}$ corresponding to cationic $\mathrm{Ir}^{4+}[28]$. No apparent bands at ca. $60.8 \mathrm{eV}$ typical of metallic iridium were observed [29] except for the fresh Ir/Si350 sample where a minor feature with intensity slightly lower than $1 \%$ at. weight was tentatively detected. Unfortunately, this value was very close to the detection limit of the XPS technique for this Ir $4 \mathrm{f}$ band ( $1 \%$ at. weight), and thus, should be carefully considered. For all samples, a majority of the iridium surface species detected at lower binding energy $\operatorname{Ir}^{3+}$ (from 68 to $85 \%$ ) is observed. In accordance to the XRD and TEM results, the only iridium species detected in the catalysts calcined at temperature higher than $450^{\circ} \mathrm{C}$ were $\mathrm{IrO}_{2}$, in which iridium presents an oxidation state of +4 . Thus, the presence of high amounts of $\mathrm{Ir}^{3+}$ could be linked to the partial reduction of $\mathrm{Ir}^{4+}$ from $\mathrm{IrO}_{2}$ as a result of 
the vacuum required for the XPS experiments. Thus, the highest proportion of $\mathrm{Ir}^{3+}$ could be associated to an easier reduction of Ir-species. Accordingly, the calcination temperature is shown to have an influence on the oxidation state observed by XPS, with the concentration of low valence iridium decreasing with the calcination temperature (Figure 9B) as it does the reducibility of the catalysts. However, it cannot be completely ruled out that the presence of $\mathrm{Ir}^{3+}$ species can be associated to the presence of oxygen vacancies in the $\mathrm{IrO}_{2}$ particles (surface poorer in oxygen).

In the case of Si $2 p$ core level (Figure 9C) only one broad peak can be observed for all the catalysts located around $103.5 \mathrm{eV}$, in line with the literature data [27]. The binding energy value and the absence of orbital splitting is in agreement with the support employed $\left(\mathrm{SiO}_{2}\right)$ where the only oxidation state is $\mathrm{Si}^{+4}$. In all the catalysts, the $\mathrm{O} 1 \mathrm{~s}$ core level (Figure 9D) presents a broad peak located at around $532.9 \mathrm{eV}$ corresponding to the $\mathrm{O}^{2-}$ present in the support $\left(\mathrm{SiO}_{2}\right)$. Due to the low concentration of iridium species in these catalysts, no signal corresponding to the $\mathrm{O}$ species present in the metallic oxide $\left(\mathrm{IrO}_{2}\right)$ was observed, making complex the identification of the nature of the active sites and their effect on the oxidation activity. 

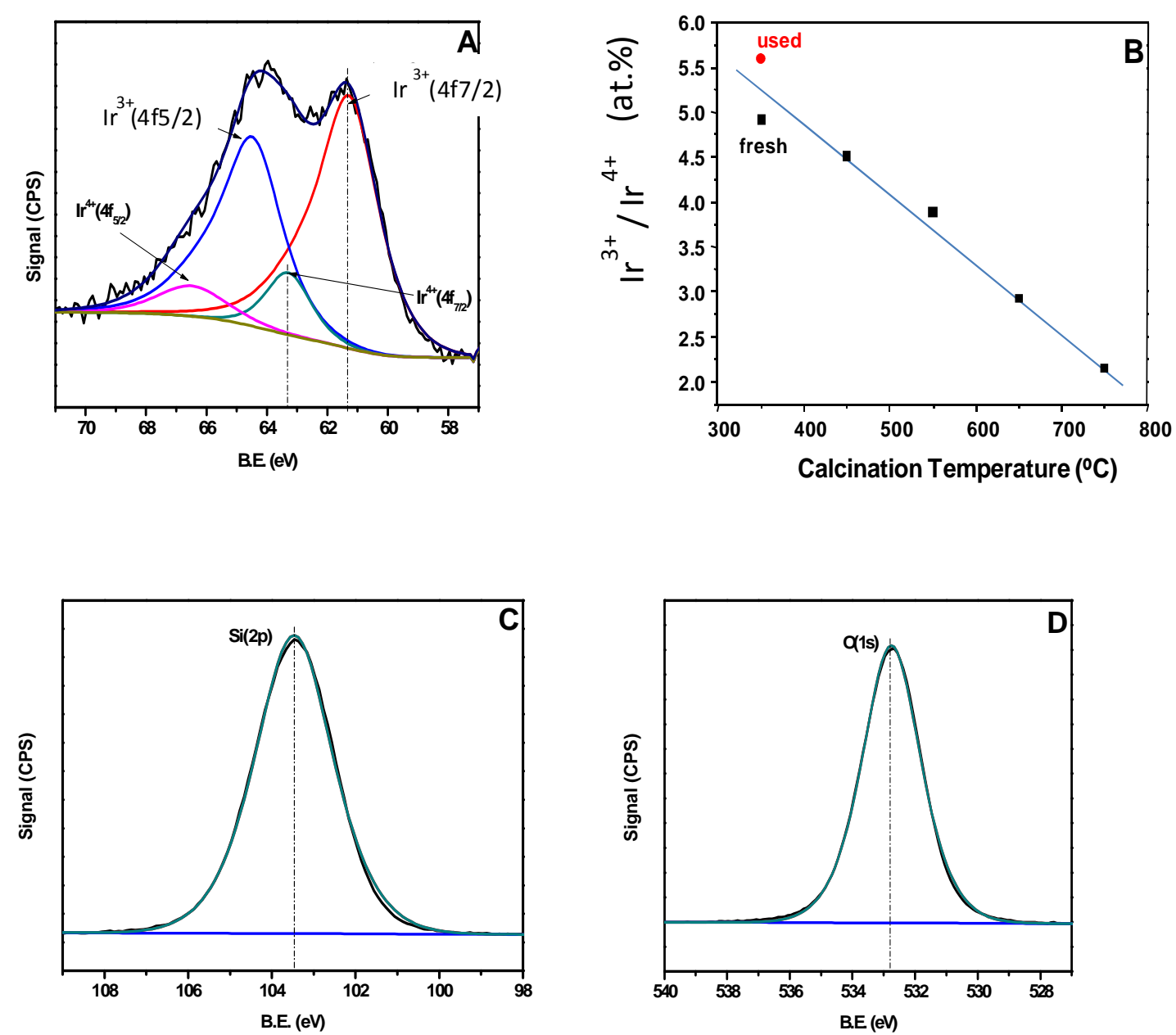

Figure 9. XPS spectra for the Ir/Si450 catalyst corresponding to Ir4f (A), Si2p (C) and O1s (D) core levels respectively. (B) Relationship between calcination temperature and surface $\mathrm{Ir}$ oxidation state $\left(\mathrm{Ir}^{3+} / \mathrm{Ir}^{4+}\right)$ of the different catalysts.

The chemical bonds in the active species have been investigated by Raman spectroscopy and the resulting spectra are given in Figure S6. All Raman spectra for the silica supported iridium catalysts consist of the background of silica in which different peaks of iridium oxide can be observed. First-order Raman spectra of iridium oxide are characterised by four typical Raman active phonon modes and include 561 (Eg), 728 (B2g), $752(\mathrm{~A} 1 \mathrm{~g}) \mathrm{cm}^{-1}$ and a very small peak at $145(\mathrm{~B} 1 \mathrm{~g}) \mathrm{cm}^{-1}$ [36]. In our spectra, only the iridium oxide peaks at ca. 561 and ca. $728 \mathrm{~cm}^{-1}$, corresponding to respectively 
Eg and A1g symmetries, are observed. Moreover, no peaks corresponding to metallic iridium or other iridium containing phases are observed. It can be seen that, in the different spectra, the iridium oxide bands present similar wideness which implies that the level of disorder in the crystalline structure is relatively similar and can be related to the relatively large size of the iridium oxide crystal phases. When the spectra are compared, a very subtle shift of the iridium oxide peaks to higher Raman shifts can be noticed when increasing calcination temperatures. Since higher Raman shifts correspond to shorter bonds, this shift suggests that the strength of the Ir-O bond increases for higher calcination temperatures.

\section{Discussion}

\subsection{On the catalytic activity of supported Ir catalysts}

Silica supported iridium catalysts calcined at low temperatures have been shown as reasonably active in the total oxidation of propane, even more than a comparable catalyst presenting palladium. $\mathrm{Ir} / \mathrm{SiO}_{2}$ catalysts are characterized by the presence of highly reducible $\mathrm{IrO}_{2}$ nanoparticles with a size that increases with the calcination temperature. Additionally, it should be mentioned that in Ir/Si catalysts, the amount of cationic $\mathrm{Ir}^{4+}$ surface species observed by XPS is considerably low despite that bulk $\mathrm{IrO}_{2}$ has been observed by XRD and microscopy data, again probing that highly reducible Ir species are available. Unfortunately, reducibility is decreased as the $\mathrm{IrO}_{2}$ particle size is increased. On the other hand, through different techniques including microscopy, XRD and $\mathrm{CO}$ chemisorption, it has been corroborated that the increase in the calcination temperature leads to an expected increase of the particle size. This enlargement of the particles is due to the sintering and aggregation of the $\mathrm{IrO}_{2}$ molecules when the 
temperature increases as the $\mathrm{IrO}_{2}$ molecules become more mobile. The notable sintering observed in the silica catalysts are due to the low interaction between $\operatorname{Ir}(\mathrm{AcAc})_{3}$ (i.e. the AcAcH group) and the surface of the $\mathrm{SiO}_{2}$ support. This observation is contrary to those with other supports such as alumina and titania, in which the support interacts with the AcAcH group leading to the formation of surface Al-acacx and Ti-acacx species [37-40] and consequently a strong interaction between the metal and the support takes place. The nature of the support can influence the dispersion and sintering of the active metal particles and affect the electronic structure i.e. the oxidation state of the active element and the reducibility and therefore, strongly affecting the resulting catalytic activity of the catalyst. The dispersion of the active metal particles on the support is influenced by the interaction of the support with the active metal, which can be described using the interfacial surface energies of both the support and the active metal. Metal particles can form chemical bonds with the support or interact only due to Van der Waals interactions. Moderate interaction with the support can suppress deactivation caused by particle sintering due to Ostwald ripening. If the interaction between active metal and support is too high, the particle can migrate into the support resulting in less active catalytic surface. Formed bonds between active metal and support can alter the electronic structure of the catalyst. Supports with strong metal support interaction (SMSI) draw electrons from the active metal, resulting in the formation of cationic species of the active metal [41]. Interestingly, the silica-iridium interaction is weak and the catalytic results obtained in the present work can be ascribed to the iridium species.

An important parameter to consider is the effect of iridium dispersion, and indirectly particle size, on the catalytic activity. This relationship has been already studied for palladium and platinum catalysts. In the case of palladium catalysts, many research groups agree that the alkane oxidation is a structure sensitive reaction with turnover 
rates increasing with the particle size [42-45]. Consequently, the catalytic activity is higher when large Pd crystallites are present, since oxygen could be easily activated. Other researchers did not find this relationship between particle size and TOF obtaining distinct reaction rates in catalysts with different sizes of crystallite, but without a defined trend [46]. Interesting relationships in the field of biocatalysis have also been found between activity and structure [47-48].

In the case of platinum catalysts there are several studies considering the effect of the particle size on the reactivity. In some cases, an increase in the reactivity has been observed when the particle size increases [42]. This effect is ascribed to weakened Pt-O bonds at larger Pt nanoparticles and a higher percentage of the most active (111) and (100) planes [49]. However, in other articles no effect has been observed [50].

In the case of the iridium catalysts presented in this work, the highest activity has been obtained by the catalyst calcined at the lowest temperature $\left(350^{\circ} \mathrm{C}\right)$. In order to compare the catalytic activities of the catalysts, a given temperature of $275^{\circ} \mathrm{C}$ has been used, conditions at which all catalyst are active. There is a clear relationship between catalytic activity and the mean Ir crystallite size (estimated by $\mathrm{CO}$ chemisorption) as shown in Figure 10A. Then, the higher the dispersion of the iridium particles, the higher is the reactivity of the active sites, being smaller particles more reactive than the larger ones.

However, this relationship does not consider the actual number of surface iridium species which is inversely proportional to the particle size. Thus, CO chemisorption analyses have been used to quantify the amount of active sites assuming a CO:Ir stoichiometric factor of 2 . Figure $10 \mathrm{~B}$ shows that the catalytic activity per exposed active site increases as the iridium size decreases (see also Table S2). While this relationship does not seem to be as drastic as the one shown in Figure 10A, a clear effect is observed. Therefore, unlike what is reported elsewhere for platinum and 
palladium catalysts, which several authors have proposed a structure sensitive relationship with activity increasing when the particle size increases, in iridium catalysts the presence of large particle does not seem to be beneficial.

A

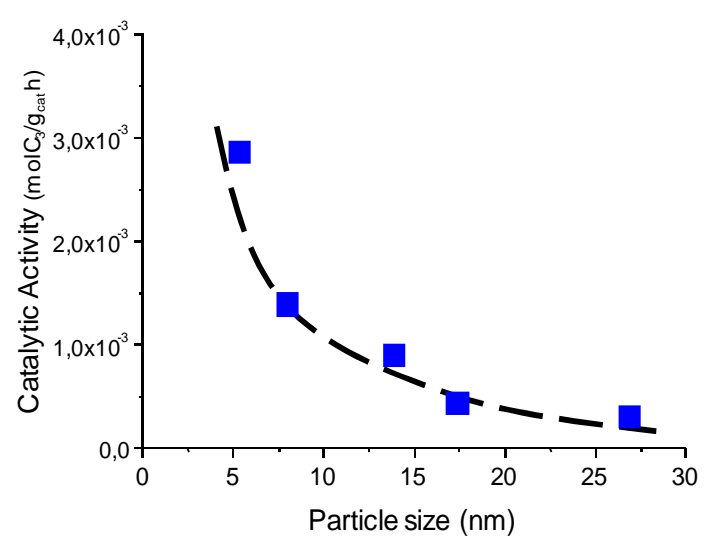

B

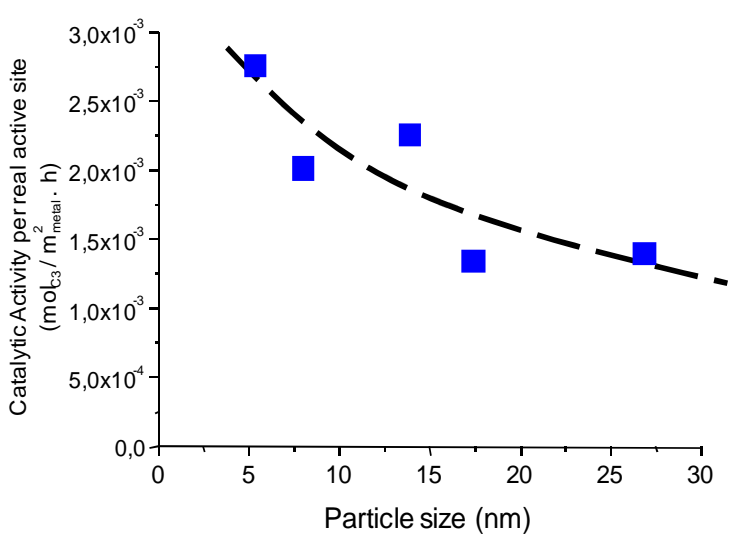

Figure 10. Effect of IrOx particle size on the propane oxidation catalytic activity. A) catalytic activity per gram of catalyst, B) catalytic activity per surface area of iridium. Reaction conditions in text at a reaction temperature of $275^{\circ} \mathrm{C}$. Note: Catalytic activity for $\mathrm{Ir} / \mathrm{Si} 350$ referred to the stabilised catalyst (after one cycle).

It must be noted that an inverse relationship has been observed between the reducibility of the catalysts and the particle size. If we consider the amount of surface $\operatorname{Ir}^{3+}$ as an estimation of the reducibility of the iridium oxide sites, in Figure S7 a clear relationship is shown, in a way that the higher the particle size the lower is the proportion of surface $\mathrm{Ir}^{3+}$ species.

A series of experiments were undertaken to provide further information of the actual parameters behind the increase of activity as the iridium particle size decreases. For this, the fresh $\mathrm{Ir} / \mathrm{Si} 350$ catalyst was loaded in the reactor under a helium flow at room temperature. After increasing the temperature at $275^{\circ} \mathrm{C}$ for 1 hour, 0.8 vol. $\%$ of propane was introduced in the inlet helium flow (no oxygen added). The conversion as a 
function of time on line was measured (Figure 11) with carbon dioxide as the only product observed. The initial propane conversion was ca. $8 \%$, a value considerably lower than that observed in the presence of oxygen $(\sim 55 \%)$ under the same reaction conditions. The propane conversion observed in the absence of oxygen decreased with the time on line and this must be due to the exhaustion of active lattice oxygen in the catalyst. Then, after only one hour online, just $1 \%$ of propane was converted towards $\mathrm{CO}_{2}$. This suggests that the propane oxidation on this iridium catalyst takes place, at least partly, by a redox Mars-Van Krevelen mechanism, in which the gas phase oxygen fed replaces the lattice oxygen consumed in the oxidation of the hydrocarbon. This proposed mechanism could not only explain the lower activity observed for the samples calcined at higher temperature, but also the deactivation process detected for the $\mathrm{Ir} / \mathrm{Si} 350$ sample, since sintered $\mathrm{IrO}_{2}$ nanoparticles after heat treatment and reaction shows a deteriorated reducibility. A similar experiment in the absence of oxygen was conducted using $\mathrm{Ir} / \mathrm{Si} 550$. The reaction temperature selected was $340^{\circ} \mathrm{C}$ as this leads to a similar propane conversion than using $\mathrm{Ir} / \mathrm{Si} 350$ catalyst at a reaction temperature of $275^{\circ} \mathrm{C}$. Using $\mathrm{Ir} / \mathrm{Si} 550$ an initial propane conversion of ca. $11 \%$ was observed, which decreased with the time on line. The trend is very similar to that observed with $\mathrm{Ir} / \mathrm{Si} 350$. This behaviour is also in line with the Mars van Krevelen mechanism. 


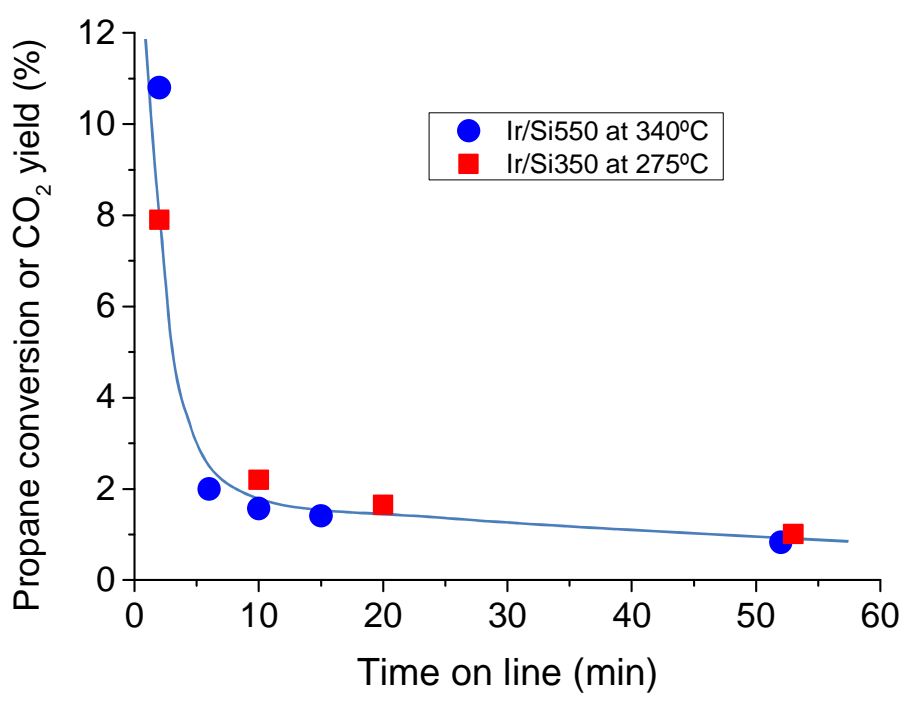

Figure 11. Evolution of the propane conversion to $\mathrm{CO}_{2}$ with the time on line in the absence of oxygen in the feed for $\operatorname{Ir} / \operatorname{Si350}(\boldsymbol{\bullet})$ and $\mathrm{Ir} / \mathrm{Si550}(\bullet)$ catalysts. Conditions: $0.80 \mathrm{vol} . \%$ propane in helium. Total flow: $50 \mathrm{ml} / \mathrm{min}, 0.1 \mathrm{~g}$ of catalyst. Reaction temperature: $275^{\circ} \mathrm{C}$ for $\mathrm{Ir} / \mathrm{Si}-350$ and $340^{\circ} \mathrm{C}$ for $\mathrm{Ir} / \mathrm{Si}-550$.

Accordingly with this proposed mechanism, the most active catalysts present high hydrogen consumption at low temperatures, related to highly reducible $\mathrm{IrO}_{2}$ nanoparticles maybe in contact with metallic Ir. This low temperature reduction peak decreases when increasing the calcination temperature. Consequently, a direct correlation between the amount of highly reducible species and the catalytic activity for alkane oxidation can be observed. In line with this, Raman spectra shows a slight displacement to higher values of the Raman shifts in the $\mathrm{IrO}_{2}$ band, when increasing the calcination temperature and this can be linked to stronger Ir-O bonds. In a Mars-Van Krevelen mechanism, weaker Ir-O bonds can be related to higher catalytic activities since the lattice oxygen is taken easier and then used to oxidise hydrocarbon. Therefore, increasing the calcination temperature shorter Ir-O bonds are apparent and this could be related to the lower activity for propane oxidation. Another factor which can play a role 
in catalytic activity can be the ease for re-oxidation of the catalysts. Thus, it has been observed by TPO that iridium sites of the catalysts calcined at lower temperatures reoxidize easier (at lower temperatures) and to a higher extent than those of the catalysts calcined at higher temperatures.

We have observed that in the range studied, from 5 to $27 \mathrm{~nm}$, the smallest $\mathrm{IrO}_{2}$ particles present higher reducibility than the largest ones. This more reducible species can break more easily the $\mathrm{C}-\mathrm{H}$ and $\mathrm{C}-\mathrm{C}$ bonds of the substrates. Methane only contains strong methyl $\mathrm{C}-\mathrm{H}$ bonds which are stronger than primary $\mathrm{C}-\mathrm{H}$ bonds present in the ethane molecule. Moreover, propane contains one secondary $\mathrm{C}-\mathrm{H}$ bond which presents an even lower binding energy than primary $\mathrm{C}-\mathrm{H}$ bonds. Then as it was expected the reactivity has varied according to methane < ethane < propane

\subsection{On the deactivation of Ir samples calcined at low temperatures}

Despite the highest initial oxidation activity of the $\mathrm{Ir} / \mathrm{Si} 350$, its reactivity decreases over time. This initial high activity is not associated to the decomposition of the Ir-salt precursor as $\mathrm{Ir}-(\mathrm{AcAc})_{3}$ decomposes at $250^{\circ} \mathrm{C}$, considerably lower than $350^{\circ} \mathrm{C}$, temperature at which the catalysts was calcined. Decomposition of $\operatorname{Ir}(\mathrm{AcAc})_{3}$ takes place at $250^{\circ} \mathrm{C}$, converting the AcAc group in the salt into $\mathrm{CO}, \mathrm{CO}_{2}$, carbonates and water while iridium is transformed into $\mathrm{IrO}_{2}[34,51]$. Although the decomposition temperature could be affected by the presence of the support, the carbon balance during the propane oxidation tests was close to $100 \%$, suggesting that the $\mathrm{CO}_{2}$ formation was only due to the total oxidation of propane and not due to the decomposition of the impregnated iridium salt. Moreover, $\operatorname{Ir}(\mathrm{AcAc})_{3}$ has not been detected by XRD. Further confirmation that the $\mathrm{CO}_{2}$ observed during the reaction is not formed by decomposition 
of the iridium precursor was obtained by heating the $\mathrm{Ir} / \mathrm{Si} 350$ catalyst at $275^{\circ} \mathrm{C}$ under a flow of He and synthetic air separately. In both cases, no $\mathrm{CO}_{2}$ was detected.

The used Ir/Si350 catalyst was characterized by a combination of analytical techniques in order to determine the cause for the deactivation. TPR experiments clearly show that after the oxidation reaction, the most reducible iridium species (initially reduced at $c a$. $95^{\circ} \mathrm{C}$ ) are partially exhausted. The loss of these active sites could be associated to the drop of the initial reactivity. HR-TEM analyses show that the fresh catalyst presents metallic $\mathrm{Ir}$ in close contact to $\mathrm{IrO}_{2}$ nanoparticles. Conversely, the used catalyst only displays $\mathrm{IrO}_{2}$, the amount of metallic Ir being negligible. It can be postulated that the simultaneous presence of both metallic $\mathrm{Ir}$ and $\mathrm{IrO}_{2}$ increases the performance of the catalyst and this effect could be related to the activation of oxygen at low temperature on the metal Ir nanoparticles, which can be transferred to the chemisorbed reactant for its total oxidation. However, under reaction conditions, metallic Ir in close contact to $\mathrm{IrO}_{2}$ nanoparticles tends to be sintered into larger $\mathrm{IrO}_{2}$ nanoparticles, instead of being again reduced to metallic Ir by propane during the redox cycle, leading to a $\mathrm{IrO}_{2}$ nanoparticle with lower reducibility and, in turn, catalytic activity. The deactivation of this catalyst is neither due to the formation of coke on the surface as in both fresh and used catalysts the amount of carbon detected are similar and negligible.

\section{Conclusions}

Iridium catalysts supported on silica show a high activity toward the total oxidation of short chain alkanes even higher than similar Pd or Au catalysts, although lower than Ptbased systems. The calcination temperature of the $\mathrm{Ir} / \mathrm{SiO}_{2}$ catalysts have a high impact on the reactivity, with decreasing activity as the treatment temperature increases associated to two effects. Firstly, increasing the calcination temperature leads to the 
agglomeration of the iridium particles from $c a .5 \mathrm{~nm}$ (at $350^{\circ} \mathrm{C}$ ) to $c a .27 \mathrm{~nm}$ (at $750^{\circ} \mathrm{C}$ ). Contrary to the $\mathrm{Pd}$ or Pt catalysts, this study demonstrates that the smaller the particle size, the higher the oxidation activity. This size effect is not only associated to an increase on $\mathrm{IrO}_{2}$ surface area as a similar trend is observed respect to particle size when the activity is calculated per metallic surface area. Secondly, increasing the calcination temperature of the $\mathrm{Ir} / \mathrm{SiO}_{2}$ catalysts the reducibility of the Ir-sites decrease, the ease for re-oxidation lowers and the strength of Ir-O bonds increases. These sites are known to be highly active for reactions following a Mars-Van Krevelen mechanism, as demonstrated here for the total oxidation of short chain alkanes.

Despite the high initial activity of the $\mathrm{Ir} / \mathrm{SiO}_{2}$ catalyst calcined at $350^{\circ} \mathrm{C}$, its activity decreases with time under reaction conditions before reaching a stable value due to the oxidation of the $\mathrm{Ir}$ and $\mathrm{IrO}_{2}$ species present in the fresh catalyst to larger $\mathrm{IrO}_{2}$ particles. On the other hand, calcination at $450^{\circ} \mathrm{C}$ and over led to the formation of stable catalysts without apparent deactivation.

\section{Acknowledgments}

Authors from UV thank the University of Valencia (UV-INV-AE16-484416 project) and MINECO (MAT2017-84118-C2-1-R project) for funding. Mathias Van de Vyver is acknowledged for the Raman study. T.G. would also like to thank the Regional Government of Aragón (DGA) for the support provided under the research groups support programme. 


\section{References}

1. B.C. McDonald, J.A. de Gouw, J.B. Gilman, S.H. Jathar, A. Akherati, C.D. Cappa, J.L. Jimenez, J. Lee-Taylor, P.L. Hayes, S.A. McKeen, Y.Y. Cui, S.W. Kim, D.R. Gentner, G. Isaacman-VanWertz, A.H. Goldstein, R.A. Harley, G.J. Frost, J.M. Roberts, T.B. Ryerson, M. Trainer, Volatile chemical products emerging as largest petrochemical source of urban organic emissions, Science 359 (2018) 760-764.

2. H. Huang, Y. Xu, Q. Feng, D.Y.C. Leung, Low temperature catalytic oxidation of volatile organic compounds: a review, Catal. Sci. Technol. 5 (2015) 26492669.

3. T. Garcia, B. Solsona, S.H. Taylor, The Catalytic Oxidation of Hydrocarbon Volatile Organic Compounds. Handbook of Advanced Methods and Processes in Oxidation Catalysis, ed. D. Duprez, F. Cavani, Imperial College Press (2014) $51-90$.

4. A. Berenjian, N. Chan, H.J. Malmiri, Volatile Organic Compounds Removal Methods: A Review, Am. J. Biochem. Biotechnol. 8 (2012) 220-229.

5. T.V. Choudhary, S. Banerjee, V.R. Choudhary, Catalysts for combustion of methane and lower alkanes, Appl. Catal. A-Gen. 234 (2002) 1-23.

6. M.S. Kamal, S.A. Razzak, M.M. Hossain, Catalytic oxidation of volatile organic compounds (VOCs) - A review, Atmos. Environ. 140 (2016) 117-134.

7. J. Liu, S. Krajangsri, J. Yang, Jia-Qi Li \& P. G. Andersson, Iridium-catalysed asymmetric hydrogenation of allylic alcohols via dynamic kinetic resolution, Nat. Catal. 1 (2018) 438-443.

8. S.K. Cheah, L. Massin, M. Aouine, M.C. Steil, J. Fouletier, P. Gélin, Methane steam reforming in water deficient conditions on $\mathrm{Ir} / \mathrm{Ce}_{0.9} \mathrm{Gd}_{0.1} \mathrm{O}_{2-\mathrm{x}}$ catalyst: 
Metal-support interactions and catalytic activity enhancement, Appl. Catal. B: Environ. 234 (2018) 279-289.

9. J. Ternel, J.L. Couturier, J.L. Dubois, J.F. Carpentier, Rhodium versus Iridium Catalysts in the Controlled Tandem Hydroformylation-Isomerization of Functionalized Unsaturated Fatty Substrates, ChemCatChem 7(3) (2015) 513520.

10. A. Haas, S. Rabl, M. Ferrari, V. Calemma, J. Weitkamp, Ring opening of decalin via hydrogenolysis on Ir/- and Pt/silica catalysts, Appl. Catal. A: Gen. 425-426 (2012) 97-109.

11. D.A. Petrone, M. Isomura, I. Franzoni, S. L. Rössler, E. M. Carreira, Allenylic Carbonates in Enantioselective Iridium-Catalyzed Alkylations, J. Am. Chem. Soc. 140(13) (2018) 4697-4704.

12. G.C. da Silva, M.R. Fernandes, E.A. Ticianelli, Activity and Stability of $\mathrm{Pt} / \mathrm{IrO}_{2}$ Bifunctional Materials as Catalysts for the Oxygen Evolution/Reduction Reactions, ACS Catal. 8 (2018) 2081-2092.

13. A.H. Pizarro, C.B. Molina, J.L.G. Fierro, J.J. Rodriguez, On the effect of Ce incorporation on pillared clay-supported Pt and Ir catalysts for aqueous-phase hydrodechlorination, Appl. Catal. B: Environ. 197 (2016) 236-243.

14. C. Zhang, Q. Lai, J.H. Holles, Ir@Pt bimetallic overlayer catalysts for aqueous phase glycerol hydrodeoxygenation, Appl. Catal. A: Gen. 526 (2016) 113-125.

15. A.J. Pamphile-Adrián, P.P. Florez-Rodriguez, M. H.M. Pires, G. Perez, F.B. Passos, Selective hydrogenolysis of glycerol over Ir-Ni bimetallic catalysts, Catal. Today 289 (2017) 302-308. 
16. M.S. Avila, C.I. Vignatti, C.R. Apesteguía, T.F. Garetto, Effect of support on the deep oxidation of propane and propylene on Pt-based catalysts, Chem. Eng. J. 241 (2014) 52-59.

17. Y. Yazawa, H. Yoshida, N. Takagi, S. Komai, A. Satsuma, T. Hattori, Oxidation state of palladium as a factor controlling catalytic activity of $\mathrm{Pd} / \mathrm{SiO}_{2}-\mathrm{Al}_{2} \mathrm{O}_{3}$ in propane combustion, Appl. Catal. B: Environ. 19 (1998) 261-266.

18. C.P. O'Brien, G.R. Jenness, H. Dong, D.G. Vlachos, I.C. Lee, Deactivation of $\mathrm{Pt} / \mathrm{Al}_{2} \mathrm{O}_{3}$ during propane oxidation at low temperatures: Kinetic regimes and platinum oxide formation, J. Catal. 337 (2016) 122-132.

19. T. Wang, L.D. Schmidt, Morphology and redispersion of Ir on $\mathrm{SiO}_{2}$ in oxidizing and reducing atmospheres, J. Catal. 66 (1980) 301-315.

20. P. Wynblatt, N.A. Gjostein, Supported metal crystallites, Prog. Solid State Chem. 9 (1975) 21-58.

21. R.M.J. Fiedorow, B.S. Chahar, S.E. Wanke, The sintering of supported metal catalysts: II. Comparison of sintering rates of supported Pt, Ir, and Rh catalysts in hydrogen and oxygen, J. Catal. 51 (1978) 193-202.

22. H. Ohtsuka, The Oxidation of Methane at Low Temperatures Over ZirconiaSupported Pd, Ir and Pt Catalysts and Deactivation by Sulfur Poisoning, Catal. Lett. 141 (2011) 413-419.

23. V.P. Santos, S.A.C. Carabineiro, P.B. Tavares, M.F.R. Pereira, J. J.M. Órfão, J.L. Figueiredo, Oxidation of $\mathrm{CO}$, ethanol and toluene over $\mathrm{TiO}_{2}$ supported noble metal catalysts, Appl. Catal. B: Environ. 99 (2010) 198-205.

24. R. T. Downs, K. L. Bartelmehs, G. V. Gibbs, M. B. Boisen, Interactive software for calculating and displaying X-ray or neutron powder diffractometer patterns of crystalline materials, Am. Mineral. 78 (1993) 1104-1107. 
25. L. Torrente-Murciano, B. Solsona, S. Agouram, R. Sanchis, J.M. López, T. García, R. Zanella, Low temperature total oxidation of toluene by bimetallic Au-Ir catalysts, Catal. Sci. Technol. 7 (2017) 2886-2896.

26. M. Montes, F.P. Getton, M.S.W. Vong, P.A. Sermon, Titania on silica. A comparison of sol-gel routes and traditional methods, J. Sol-Gel Sci. Technol. 8 (1997) 131-137.

27. T. Marzialetti, M. Oportus, D. Ruiz, J. L. García-Fierro, P. Reyes, Enantioselective hydrogenation of 1-phenyl-1,2-propanedione, ethyl pyruvate and acetophenone on $\mathrm{Ir} / \mathrm{SiO}_{2}$ catalysts: Effect of iridium loading, Catal. Today 133-135, 2008, 711-719.

28. N.K. Hon, R. Soref, B. Jalali, Impact of metal nanolayer thichness on tunneling oxide and memory performance of core-shell iridium-oxide nanocrystals, J. Appl. Phys. 110 (2011) 011301-1-8.

29. V. Pfeifer, T.E. Jones, J.J. Velasco Vélez, C. Massué, R. Arrigo, D. Teschner, F. Girgsdies, M. Scherzer, M.T. Greiner, J. Allan, M. Hashagen, G. Weinberg, S. Piccinin, M. Hävecker, A. Knop-Gerickea, R. Schlögl, The electronic structure of iridium and its oxides, Surf. Interface Anal. 48 (2016) 261-273.

30. S.E. Deutsh, J.T. Miller, K. Tomishige, Y. Iwasawa, W.A. Weber, B.C. Gates, Supported Ir and Pt Clusters: Reactivity with Oxygen Investigated by Extended X-ray Absorption Fine Structure Spectroscopy, J. Phys. Chem. 100 (1996) 13408-13415.

31. G. Veser, M. Ziauddin, L.D. Schmidt, Ignition in alkane oxidation on noblemetal catalysts, Catal. Today 47 (1999) 219-228. 
32. B.J. Kip, J. Van Grondelle, J.H.A. Martens, R. Prins, Preparation and characterization of very highly dispersed iridium on $\mathrm{Al}_{2} \mathrm{O}_{3}$ and $\mathrm{SiO}_{2}$, Appl. Catal. 26 (1986) 353-373.

33. B.J. Kip, F.B.M. Duivenvoorden, D.C. Koningsberger, R. Prins, Determination of metal particle size of highly dispersed Rh, Ir, and Pt catalysts by hydrogen chemisorption and EXAFS, J. Catal. 105 (1987) 26-38.

34. F. Locatelli, B. Didillon, D. Uzio, G. Niccolai, J.P. Candy, J. M. Basset, Preparation and Characterization of Small Silica-Supported Iridium Particles from Iridium Trisacetylacetonate Precursor, J. Catal. 193 (2000) 154-160.

35. L. Torrente-Murciano, The importance of particle-support interaction on particle size determination by gas chemisorption, J. Nanopart. Res. (2016) 18:87.

36. Y. S. Huang, S. S. Lin, C. R. Huang, M. C. Lee, T. E. Dann, and F. Z. Chien, Raman spectrum of $\mathrm{IrO}_{2}$, Solid State Commun. 70(5) (1989), 517-522.

37. R.J. Silvennoinen, O.J.T. Jylhä, M. Lindblad, H. Österholm, A.O.I. Krause, Supported iridium catalysts prepared by atomic layer deposition: effect of reduction and calcination on activity in toluene hydrogenation, Catal. Lett. 114 (2007) 135-144.

38. R.J. Silvennoinen, O.J.T. Jylhä, M. Lindblad, J.P. Sainio, R.L. Puurunen, A.O.I. Krause, Atomic layer deposition of iridium(III) acetylacetonate on alumina, silica-alumina, and silica supports, Appl. Surf. Sci. 253 (2007) 4103-4111.

39. J.A.R. van Veen, G. Jonkers, W.H. Hesselink, Interaction of transition-metal acetylacetonates with $\gamma-\mathrm{Al}_{2} \mathrm{O}_{3}$ surfaces, J. Chem. Soc. Faraday Trans. 1, 85 (1989) 389-413. 
40. A. Rautiainen, M. Lindblad, L.B. Backman, R.L. Puurunen, Preparation of silica-supported cobalt catalysts through chemisorption of cobalt(II) and cobalt(III) acetylacetonate, Phys. Chem. Chem. Phys. 4 (2002) 2466-2472.

41. P Reyes, M.C Aguirre, G Pecchi, J.L. Garcia-Fierro, Crotonaldehyde hydrogenation on Ir supported catalysts, J. Mol. Catal. A: Chem. 164 (2000) $245-251$.

42. R.F. Hicks, H. Qi, M.L. Young, R.G. Lee, Structure sensitivity of methane oxidation over platinum and palladium, J. Catal. 122 (1990) 280-294.

43. P. Briot, M. Primet, Catalytic oxidation of methane over palladium supported on alumina : Effect of aging under reactants, Appl. Catal. 68 (1991) 301-314.

44. K.I. Fujimoto, F.H. Riberio, M. Avalos-Borja, E. Iglesia, Structure and Reactivity of $\mathrm{PdO}_{\mathrm{x}} / \mathrm{ZrO}_{2}$ Catalysts for Methane Oxidation at Low Temperatures, J. Catal. 179 (1998) 431-442.

45. R.F. Hicks, H. Qi, M.L. Young, R.G. Lee, Effect of catalyst structure on methane oxidation over palladium on alumina, J. Catal. 122 (1990) 295-306.

46. T.R. Baldwin, R. Burch, Catalytic combustion of methane over supported palladium catalysts: I. Alumina supported catalysts, Appl. Catal. 66 (1990) 337358.

47. Y. Huang, Z. Liu, C. Liu, E. Ju, Y. Zhang, J. Ren, X. Qu, Self-Assembly of Multi-nanozymes to Mimic an Intracellular Antioxidant Defense System, Angew. Chem. Int. Ed. 55 (2016) 6646-6650.

48. H. Wang, P. Li, D. Yu, Y. Zhang, Z. Wang, C. Liu, H. Qiu, Z. Liu, J. Ren, X. Qu, Unraveling the Enzymatic Activity of Oxygenated Carbon Nanotubes and Their Application in the Treatment of Bacterial Infections, Nano Lett. 18 (2018) $3344-3351$. 
49. H. Huang, P. Hu, H. Huang, J. Chen, X. Ye, D.Y.C. Leung, Highly dispersed and active supported Pt nanoparticles for gaseous formaldehyde oxidation: Influence of particle size, Chem. Eng. J. 252 (2014) 320-326.

50. R. Burch, P.K. Loader, Investigation of $\mathrm{Pt} / \mathrm{Al}_{2} \mathrm{O}_{3}$ and $\mathrm{Pd} / \mathrm{Al}_{2} \mathrm{O}_{3}$ catalysts for the combustion of methane at low concentrations, Appl. Catal. B: Environ. 5 (1994) $149-164$.

51. S. Nassreddine, G. Bergeret, B. Jouguet, C. Geantet, L. Piccolo, Operando study of iridium acetylacetonate decomposition on amorphous silica-alumina for bifunctional catalyst preparation, Phys. Chem. Chem. Phys. 12 (2010) 78127820. 
